\title{
The Epidemic of Mental Disorders in Business-How Depression, Anxiety, and Stress Spread across Organizations through Employee Mobility
}

Citation for published version (APA):

Kensbock, J. M., Alkaersig, L., \& Lomberg, C. (2022). The Epidemic of Mental Disorders in Business-How Depression, Anxiety, and Stress Spread across Organizations through Employee Mobility. Administrative Science Quarterly, 67(1), 1-48. [00018392211014819]. https://doi.org/10.1177/00018392211014819

Document status and date:

Published: 01/03/2022

DOI:

10.1177/00018392211014819

Document Version:

Publisher's PDF, also known as Version of record

Document license:

Taverne

Please check the document version of this publication:

- A submitted manuscript is the version of the article upon submission and before peer-review. There can be important differences between the submitted version and the official published version of record.

People interested in the research are advised to contact the author for the final version of the publication, or visit the DOI to the publisher's website.

- The final author version and the galley proof are versions of the publication after peer review.

- The final published version features the final layout of the paper including the volume, issue and page numbers.

Link to publication

\footnotetext{
General rights rights.

- You may freely distribute the URL identifying the publication in the public portal. please follow below link for the End User Agreement:

www.umlib.nl/taverne-license

Take down policy

If you believe that this document breaches copyright please contact us at:

repository@maastrichtuniversity.nl

providing details and we will investigate your claim.
}

Copyright and moral rights for the publications made accessible in the public portal are retained by the authors and/or other copyright owners and it is a condition of accessing publications that users recognise and abide by the legal requirements associated with these

- Users may download and print one copy of any publication from the public portal for the purpose of private study or research.

- You may not further distribute the material or use it for any profit-making activity or commercial gain

If the publication is distributed under the terms of Article 25fa of the Dutch Copyright Act, indicated by the "Taverne" license above, 


\section{The Epidemic of}

Mental Disorders in

Business-How

Depression, Anxiety,

and Stress Spread

across Organizations

through Employee

Mobility
Administrative Science Quarterly $1-48$

(C) The Author(s) 2021

Article reuse guidelines:

sagepub.com/journals-permissions DOI: $10.1177 / 00018392211014819$ journals.sagepub.com/home/asq

@SAGE

\title{
Julia M. Kensbock, ${ }^{1}$ (D) Lars Alkærsig, ${ }^{2}$ (i) and Carina Lomberg ${ }^{2 *}$ (I)
}

\begin{abstract}
Combining management research with infectious disease epidemiology, we propose a new perspective on mental disorders in a business context. We suggest that-similar to infectious diseases-clinical diagnoses of depression, anxiety, and stress-related disorders can spread epidemically across the boundaries of organizations via social contagion. We propose a framework for assessing the patterns of disease transmission, with employee mobility as the driver of contagion across organizations. We empirically test the proposed mental disorder transmission patterns by observing more than 250,000 employees and more than 17,000 Danish firms over a period of 12 years. Our findings reveal that when organizations hire employees from other, unhealthy organizations (those with a high prevalence of mental disorders), they "implant" depression, anxiety, and stress-related disorders into their workforces. Employees leaving unhealthy organizations act as "carriers" of these disorders regardless of whether they themselves have received a formal diagnosis of a mental disorder. The effect is especially pronounced if the newcomer holds a managerial position.
\end{abstract}

Keywords: mental disorders, contagion, epidemic, employee mobility

Mental disorders are widespread in populations worldwide, and the rates of individuals affected continue to rise (e.g., Twenge et al., 2019). A mental

\footnotetext{
* Corresponding author: Carina Lomberg, calom@dtu.dk

${ }^{1}$ Maastricht University

${ }^{2}$ Technical University of Denmark
} 
disorder is "a major disturbance in an individual's thinking, feelings, or behavior" that causes problems "in social, work, or family activities" (APA, 2015). In the United States, the projected risk of developing some type of mental disorder throughout one's lifetime is higher than 50 percent (Kessler et al., 2005). According to Schaefer and colleagues (2017), the number of individuals who remain free of a mental disorder during their lifetime is remarkably small. Organizations should find these statistics alarming, since clinical manifestations of mental disorders are among the most frequent causes of long-term sickness absence (Mittendorfer-Rutz et al., 2012; Suzuki et al., 2015) and work disability (Mathers and Loncar, 2006; Vos et al., 2012). Reducing the occurrence of mental disorders and fostering individual health and well-being should be not only societal and political goals but also key management objectives (Chisholm et al., 2016; George et al., 2016).

This study examines how clinical diagnoses of three of the most frequent mental disorders (Steel et al., 2014)—depression, anxiety, and stress-related disorders-spread across separate organizations through employee mobility and social contagion. ${ }^{\mathbf{1}}$ Using infectious disease epidemiology (MacMahon and Pugh, 1970; Porta, 2014) as a metaphor, we raise the question of what happens after employees leave "unhealthy" organizations that have high numbers of employees with mental disorders. We suggest that-just as geographic mobility facilitates the spread of infectious diseases (e.g., COVID-19; Kraemer et al., 2020)—employee mobility facilitates the spread of depression, anxiety, and stress-related disorders into "healthy" organizations: those that have low numbers of employees with mental disorders. ${ }^{2}$

In describing transmission patterns across organizations, we offer a new perspective on mental disorders that goes beyond the borders of single organizations. This is important as organizations are not isolated and stable ecosystems but, in times of high employee mobility (Raffiee and Byun, 2020), constantly hiring new employees from external workforces, including individuals "carrying" mental disorders. Thus mental disorders may not only start within the borders of a given organization but also arise beyond its borders.

We test our assumptions empirically using comprehensive longitudinal, population-wide, individual-level and firm-level data from Denmark to allow a long-term observation of mental disorders among employees and their employing organizations. Our study provides several important results. We find that employee mobility facilitates the transmission of depression, anxiety, and stress-related disorders across organizational borders. Newcomers who are diagnosed with mental disorders or who leave unhealthy organizations to start new jobs in other organizations serve as "carriers" of these mental disorders

\footnotetext{
1 "Mental disorders" is an umbrella term for a broad range of diagnoses that also include, e.g., personality disorders, psychoses, and developmental disorders (WHO, 2019). This study focuses on depression, anxiety, and stress-related disorders — three mental disorders that have been intensively discussed in the workplace context (e.g., Karasek, 1979; Bhui et al., 2012; Hendriks et al., 2015; Suzuki et al., 2015; Joyce et al., 2016). Thus when referring to "mental disorders" in the context of this study, we refer to depression, anxiety, and stress-related disorder diagnoses.

2 In speaking of "healthy" vs. "unhealthy" organizations, we use a simplified distinction to help readers visualize the differences between organizations with particularly low or high numbers of employees with mental disorders. However, we understand the (un)healthiness of organizations as a continuum, not as a binary concept. Therefore, beyond very healthy and very unhealthy organizations, organizations with medium "healthiness" (i.e., medium proportions of employees with mental disorders) do of course exist.
} 
and can "implant" mental disorders into the hiring organization, initiating a chain of contagion among the existing employees.

The finding that depression, anxiety, and stress-related disorders are longlasting and pervasive enough to cross over organizational borders and initiate contagion effects within hiring organizations challenges established positive views about employee mobility held in the domains of organizational behavior, occupational health research, and strategic management. We contribute to this research in several important ways. From an employee-level perspective, our finding that mental disorder symptoms can persist across organizations challenges the view that a job change into a more favorable work environment can be a cure for psychological problems experienced at work (De Lange et al., 2005; De Lange, De Witte, and Notelaers, 2008). From an organizational-level perspective, the finding that employee mobility can come with a detrimental spread of mental disorders in a hiring organization challenges the dominant view that portrays external hiring as mostly beneficial for organizations based on the rationale that it provides these organizations with valuable human capital and thus competitive advantage (Barney and Wright, 1998; Hancock et al., 2013). Our study further adds to the workplace socialization literature, which has found that dysfunctional behavior (such as alcohol abuse) can spill over from an organization to newcomers entering this new environment (e.g., Burke and Cooper, 2008; Liu et al., 2015). Expanding this one-directional finding, we show that the reverse effect-a spillover from newcomers to established groups of employees in an organization-is also possible for mental disorders.

We broaden the prevailing organization-centric view on mental disorders in business by (1) extending the traditional management view that a major driver of mental disorders in the workplace lies (solely) in within-organization workrelated stressors (e.g., Follmer and Jones, 2017; Harvey et al., 2017) and (2) complementing the view that mental disorders have (only) serious withinorganization effects, e.g., for job and firm performance or absenteeism (McTernan, Dollard, and LaMontagne, 2013; Hendriks et al., 2015; Ho and Kuvaas, 2020).

\section{MENTAL DISORDERS AND EMPLOYEE MOBILITY-WHY WE NEED A NEW APPROACH TO EXPLAINING CONTAGION ACROSS ORGANIZATIONAL BOUNDARIES}

The far-reaching negative consequences of depression, anxiety, and stressrelated disorders for individuals and organizations (Mikkelsen and Rosholm, 2018) have prompted not only clinical psychologists but also management and occupational health researchers to study how mental disorders arise, i.e., their etiology. The etiology of mental disorders is complex and multifactorial and includes causes ranging from genetic vulnerability to environmental stressors (Smoller, 2016). Management researchers have focused on the latter and argued that work-related stressors, such as aversive working conditions characterized by high job demands, increase the risk of employees developing mental disorders (Karasek, 1979; Joyce et al., 2016; Follmer and Jones, 2017; Harvey et al., 2017). Indeed, wide empirical evidence shows that work-related stressors contribute to the onset or exacerbation of depression (Netterstrøm et al., 2008; McTernan, Dollard, and LaMontagne, 2013; Theorell et al., 2015), anxiety (Stansfeld and Candy, 2006; Melchior et al., 2007; Bhui et al., 2012), 
and stress-related disorders (e.g., Nieuwenhuijsen, Bruinvels, and FringsDresen, 2010; Fila, Purl, and Griffeth, 2017). While each of these conditions is characterized by distinct symptoms, they are also interrelated and have important common elements, according to the tripartite model in clinical psychology (Clark and Watson, 1991; Lovibond and Lovibond, 1995). As a result, these three mental disorders often are examined together (e.g., Gomez, 2013).

The etiologic view of mental disorders in the management field is mostly organization-centric in nature, as it implies that an organization can prevent or reduce mental disorders by reducing the organization-internal and job-specific stressors for their workforce. However, this view sees the workforce of an organization as a mostly fixed group of individuals and disregards that mental disorders might enter the organization from the outside through external hiring processes. Organizational workforces are in constant flux due to increasing employee mobility (Raffiee and Byun, 2020). While in the past organizations filled a high percentage of their job positions with internal candidates, organizations now constantly exchange human resources with other organizations (Hancock et al., 2013; Cappelli and Keller, 2014; Raffiee and Buyn, 2020). Hiring from outside the organization likely includes individuals coming from "unhealthy" organizations, since adverse working conditions are one of the main reasons for employees to seek new jobs in other organizations (Liljegren and Ekberg, 2009; Reineholm et al., 2012). Moreover, external candidate pools are likely to include candidates with mental disorders, as not only is the overall number of individuals with mental disorders growing (Weissman et al., 2017), but also those individuals with mental disorders more frequently change their jobs (see the meta-analysis by Mor Barak, Nissly, and Levin, 2001).

We suggest that using infectious disease epidemiology as a metaphor will enable a more comprehensive perspective on the effects of mental disorders across organizational boundaries. When trying to understand potential crossorganizational effects of mental disorders, management approaches with an organization-centric etiological perspective might have limited explanatory power. In contrast to other clinicians who focus on the etiology and thus the causation of diseases in individual patients, epidemiologists study the patterns, causes, and effects of diseases in groups or populations (Straif-Bourgeois, Ratard, and Kretzschmar, 2014; Frérot et al., 2018). The present study does not try to examine the etiology of employees' mental disorders. Rather, following an epidemiological approach, it shifts the focus from unhealthy individuals to unhealthy populations of employees - that is, to unhealthy organizations.

\section{Infectious Disease Epidemiology as a Metaphor to Explain Mental Disorder Contagion in the Work Context}

Epidemiology is "the study of the distribution and determinants of healthrelated states or events in specified populations, and the application of this study to the prevention and control of health problems" (Porta, 2014: 95). The central object of investigation is the spread of infectious diseases with microorganisms (e.g., influenza viruses) being part of the infection (Bonita, Beaglehole, and Kjellström, 2006). Epidemiologists also develop sophisticated mathematical models to describe these patterns and chains of infection (e.g., Kermack and McKendrick, 1927). These insights have proven so powerful that 
scholars in many unrelated fields have started using epidemiological models to explain how various kinds of human behavior spread (Patten, 1999; Dodds and Watts, 2005). An array of human behaviors has been shown to "spread through populations in a way analogous to the spread of microbial diseases" (Patten, 1999: 217), including eating disorders (González et al., 2003), obesity (Caballero, 2007; Wang et al., 2008), alcohol and drug use (Behrens et al., 2000; Benedict, 2007), group violence (Patten, 1999; Patten and ArboledaFlórez, 2004), and rumors and ideas (Moreno, Nekovee, and Pacheco, 2004; Bettencourt et al., 2016).

We suggest that infectious disease epidemiology can also be used as a metaphor for explaining how depression, anxiety, and stress-related disorders spread within and across organizations. Following the distinction between modes of disease contagion and patterns of disease distribution (Porta, 2014), we first outline how mental disorders can be transmitted from one person to another in the same environment (modes of mental disorder contagion). Here, we build upon already-known psychological mechanisms of social contagion. Second, we focus on the core and largely unexplored research question underlying our study, that is, how mental disorders spread across organizational borders. Thus, our hypotheses focus on the patterns of mental disorder distribution across populations.

Underlying modes of mental disorder contagion. Our basic assumption is that depression, anxiety, and stress-related disorders may be transferred from person to person in the work context. In contrast to modes of contagion of medical infectious diseases (e.g., touching, sneezing; Bonita, Beaglehole, and Kjellström, 2006), the psychological nature of mental disorders means that their "mode of transmission" will be a psychological process. From the early days of psychology research, scholars have applied the contagion concept to a wide range of psychological phenomena that spread within groups, including aggression, hysteria, and psychogenic illnesses (Le Bon, 1903; Goethals and Perlstein, 1978; Colligan and Murphy, 1982; see Levy and Nail, 1993 for a review). These psychological contagion effects can be subsumed under the term social contagion (Crandall, 1988; Bauch and Galvani, 2013).

Social contagion is based on humans' fundamental tendency to observe other individuals and compare to them (Kruglanski and Mayseless, 1990). When interacting with others, individuals automatically tend to observe their salient expressions (Kalish et al., 2015). Specifically, they observe how others feel (emotion), judge (cognition), and act (behavior), and they tend to respond by feeling, judging, and acting in similar ways (Barsade, 2002). Prior studies provide evidence of emotional, cognitive, and behavioral modes of social contagion (e.g., Wheeler and Caggiula, 1966; Degoey, 2000; Kelly and Barsade, 2001). Mental disorders such as depression, anxiety, and stress are observable in individuals' emotions, cognitions, and behaviors (Sapolsky, 2006; Cohn et al., 2009; APA, 2015; Shu et al., 2017). Therefore, known modes of social contagion may also play a major role in the spread of mental disorders from one employee to another.

In the case of the emotional mode of social contagion, coworkers can be influenced immediately by characteristic emotions expressed by employees with mental disorders. Emotions are not only intrapersonal but also 
interpersonal in nature, as they guide and structure social relationships with others (Keltner and Haidt, 1999; Barsade and Gibson, 2012). Depressed, fear$\mathrm{ful}$, and stress-related emotions can be readily observed in facial expressions, movements, and postures (Wallbott and Scherer, 1991; Critchley and Nagai, 2012). A large stream of research dealing with emotional contagion (see Barsade, Coutifaris, and Pillemer, 2018 for a comprehensive review) shows that during perception of emotional cues, individuals show an automatic tendency to mimic and synchronize with the expressions displayed by others (Hatfield, Cacioppo, and Rapson, 1994; Tsai et al., 2011). This results in the individual experiencing the same emotions as the counterpart (Hatfield, Cacioppo, and Rapson, 1992; Totterdell, 2000). Thus individuals interacting with coworkers displaying emotions that are characteristic of a mental disorderespecially over a long period of time-are also likely to experience these emotional symptoms, e.g., feeling depressed, fearful, or stressed (Totterdell et al., 2012; Zagenczyk, Powell, and Scott, 2020). Prior research supports the idea that emotional cues indicating depression (Joiner and Katz, 1999; Fowler and Christakis, 2008; Hill et al., 2010), anxiety (Gurtman, Martin, and Hintzman, 1990; Schwartz-Mette and Rose, 2012), and stress (Gump and Kulik, 1997; Kalish et al., 2015) are contagious.

In the context of the cognitive mode of contagion, coworkers will also be affected by the cognitions (e.g., attitudes, judgments) expressed by individuals with mental disorders. Prior research shows that such cognitions can spread via social interaction and can lead to the development of similar cognitions among other members of social groups (Degoey, 2000; Barsade, 2002). According to the information-processing approach proposed by Salancik and Pfeffer (1978: 226), the social context at work "provides cues which individuals use to construct and interpret events." For instance, if conversations with coworkers always focus on the demanding, exhausting, or threatening aspects of work or life in general, the individual will be likely also to focus on these negative cognitions and to adapt judgments accordingly (Salancik and Pfeffer, 1978). Mental disorders are associated with characteristic cognitive styles. Depressed individuals tend to hold pessimistic cognitions about themselves, their future, and the causes of events—the "cognitive triad" (Beck, 1976). Anxious and stressed individuals tend to interpret stimuli and events in their environment as overly threatening (Eysenck et al., 2007; Cheng and McCarthy, 2018). In addition, mental disorders often go along with negative attitudes to the work and work environment (Bianchi, Schonfeld, and Laurent, 2017) and negative beliefs about one's performance at work (e.g., feelings of failure in the job, worthlessness, low self-efficacy; Rottinghaus, Jenkins, and Jantzer, 2009). Prior research has shown that cognitive styles characteristic of depression (Stark, Schmidt, and Joiner, 1996; Garber and Flynn, 2001), anxiety (Barrett et al., 1996; Creswell, O'Connor, and Brewin, 2006), and stress-related disorders (Kassam-Adams et al., 2006) can be contagious. In addition, evidence related to cognitive contagion in the workplace shows that individuals' perceptions of their working conditions (Ibarra and Andrews, 1993) or attitudes toward leaders (Dasborough et al., 2009) can be contagious. Thus individuals who interact frequently with coworkers with mental disorders may start to tune into and display disorder-related mindsets.

Finally, related to the behavioral mode of contagion, coworkers will be influenced by the behavior of individuals with mental disorders and may change 
their own behavior accordingly (Latané, 2000). Employees with mental disorders show several patterns of characteristic behavior that are easily mimicked by and thus transferred to individuals around them. Depressive behavior is typically characterized by learned helplessness-a tendency to withdraw from difficult situations, reduce efforts, and quit trying (Diener and Dweck, 1978; Teodorescu and Erev, 2014). Prior research shows that depressive behavior-including learned helplessness — can be contagious (Brown and Inouye, 1978; Joiner and Katz, 1999). Even in an animal model, healthy rats start to display depressive behavior when housed with depressed rats (Boyko et al., 2015). Similarly, when faced with potentially threatening situations, individuals with anxiety-related disorders tend to show strong avoidance behavior (Cheng and McCarthy, 2018), which can be mimicked by others (Wheeler, 1966). Moreover, depressed, anxious, and stressed individuals show maladaptive coping behavior when facing stressful situations (Kramer et al., 2010; Mark and Smith, 2012a, 2012b; Van Gelderen et al., 2014). This may include avoiding work-related problems, which acts to reinforce feelings of helplessness and futility (Harkness et al., 2005). Coping behavior in the workplace has been shown to be contagious such that team members mirror avoidant coping behavior when confronted by hindrances (Pearsall, Ellis, and Stein, 2009). Taken together, this research shows that emotions, cognitions, and behaviors characteristic of depression, anxiety, and stress-related disorders are likely to spill over to and be mirrored by individuals interacting with each other.

\section{Patterns of mental disorder distribution within and across}

organizations. We suggest that using infectious disease epidemiology as a metaphor can help to understand the spreading of mental disorders within and-most importantly-across organizations. Using this metaphor, depression, anxiety, and stress-related disorders would be seen as infectious diseases that spread across populations via so-called chains of infection through emotional, cognitive, and behavioral modes of contagion between individuals (cf. Krämer, Akmatov, and Kretzschmar, 2010). Using an infectious disease epidemiology lens, we consider an employee with such a mental disorder as an infective individual or host who serves as the initial source of further infections (cf. Newman, 2002). This infective individual faces populations of susceptible individuals: those at risk of being infected with the disease (Thieme, 1977).

When diseases spread, contagion processes initially affect the individuals within the boundaries of a given population-in our case, the coworkers working together with an infective employee in the same organization. For instance, within Organization A depicted in Figure 1, the infective individual (i.e., with a mental disorder) is a member of a group of susceptible individuals (i.e., healthy employees) within the same population (i.e., Organization A). By interacting with the infective individual and via emotional, cognitive, and behavioral modes of contagion as described above, over time, some of these susceptible individuals might also develop mental disorders. Epidemiological patterns can thus explain intra-organizational contagion effects, i.e., how mental disorders could be transmitted within the boundaries of separate organizations.

In addition, these different contagion patterns explain why mental disorders accumulate more strongly in some organizations than in others (e.g., Organization A vs. Organization B in Figure 1). In epidemiological terms, 
Figure 1. Transmission of Mental Disorders within Organizational Borders*

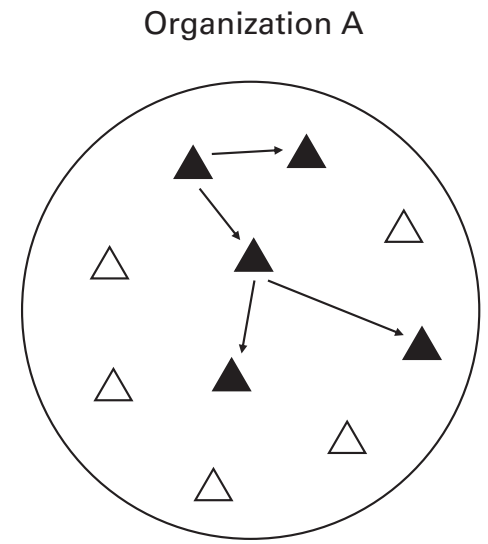

Organization B

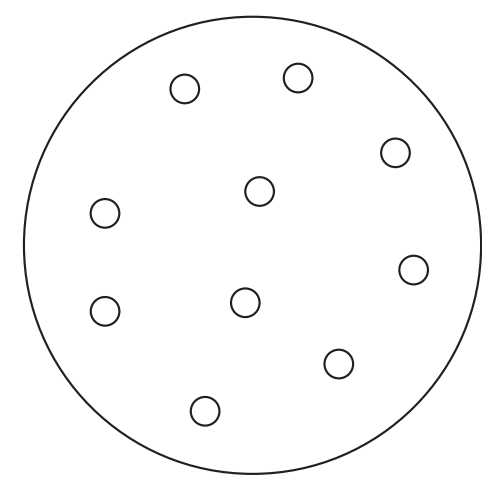

* The filled-in symbols indicate individuals with mental disorders; the blank symbols indicate individuals without mental disorders.

organizations differ in their prevalence of mental disorders: the number of infected individuals in a specified population at a given point in time (cf. Bonita, Beaglehole, and Kjellström, 2006). We use prevalence to distinguish unhealthy organizations (high prevalence; see Organization A in Figure 1) from healthy organizations (low prevalence; see Organization B in Figure 1). In the management context, the idea that organizations may be overall healthy or unhealthy has been discussed (Cooper and Cartwright, 1994; Ashkanasy and Daus, 2002; Salanova et al., 2012; Ashkanasy and Härtel, 2014) but not tested empirically. Unhealthy organizations are anecdotally described as having a depressive climate (Westman, 2001; Gamero, González-Romá, and Peiró, 2008), climate of fear/anxiety (Ashkanasy and Nicholson, 2003; Parke and Seo, 2017), or stress/ strain climate (Westman and Etzion, 1999; Rodríguez et al., 2019). Some scholars have suggested that crossover effects from one employee to another within the same team, department, and organization might be one reason why unhealthy climates arise (Westman and Etzion, 1999; Westman, 2001; Tee, 2015; Zagenczyk, Powell, and Scott, 2020). From the prevailing intraorganizational etiological view on mental disorders, organizations might also become overall unhealthy because all individuals "equally" suffer from the same stressors found in this environment (Bakker, Van Emmerik, and Euwema, 2006). As such, organizations have been seen as separate ecosystems with specific levels of mental disorders that make them overall healthier or unhealthier.

\section{Contagion effects through mobility of employees with mental}

disorders. The prevailing intra-organizational etiological view on mental disorders in the workplace can explain why mental disorders accumulate within single organizations but fails to address what happens when individuals leave an unhealthy organization and enter a new one. From the history of medical diseases such as typhus and smallpox but also the recent case of COVID-19, we know that mobility of individuals is a serious facilitator of disease 
Figure 2. Transmission of Mental Disorders across Organizational Borders*

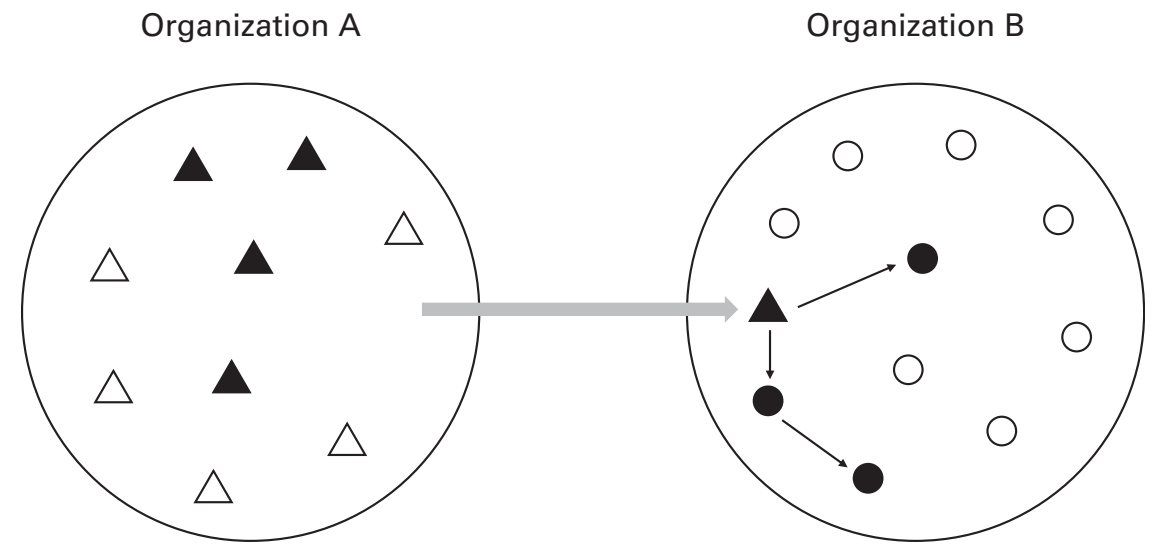

* The filled-in symbols indicate individuals with mental disorders; the blank symbols indicate individuals without mental disorders.

transmission (Smith et al., 2007; Perrings et al., 2014; Kraemer et al., 2020). Diseases can spread across spatially distributed populations when an infective individual is introduced into another distant group of susceptible individuals (Thieme, 1977). If an infective individual enters a new environment, the susceptible individuals in that population are exposed to the disease-they are put in a situation in which transmission of the disease could occur (Straif-Bourgeois, Ratard, and Kretzschmar, 2014).

We suggest that employee mobility will also facilitate the transmission of depression, anxiety, and stress-related disorders from one organization to another (see Figure 2). Building again on the metaphor of infectious diseases, a hiring organization's workforce (see the workforce of Organization B in Figure 2) might represent the population of susceptible individuals at risk of infection via a new employee diagnosed with a mental disorder (such as the employee leaving Organization A in Figure 2). For the hiring organization, knowingly or unknowingly employing a newcomer with a mental disorder may increase the likelihood that this mental disorder will enter its workforce, leading to a chain of infection among existing employees. In other words, with reference to the modes of contagion discussed above, the hiring organization's existing employees will be exposed to the emotional, cognitive, and behavioral expressions of their new coworker, increasing the likelihood of them experiencing the same symptomatology.

Combining these transmission patterns with insights from general and clinical psychology, we suggest that mental disorders and the associated social contagion effects will be (a) long-lasting enough to carry over across organizational borders and (b) pervasive enough to lead to new chains of "infections" in a hiring organization.

First, since prior management research links mental disorders to organization-internal stressors, it implicitly suggests that mental disorders may desist after leaving an unhealthy work environment. Escaping an unhealthy organization and starting again in a new work environment has been proposed to reduce job strain and demands (Swaen et al., 2002; De Lange et al., 2005), 
create new resources (De Lange, De Witte, and Notelaers, 2008), and provide personal growth (De Croon et al., 2004). Consequently, job mobility has been discussed as a promising strategy for individuals to sustain their health and well-being and to recover from their mental disorders (Wright and Bonett, 1992; Liljegren and Ekberg, 2009; Equeter, Jepsen, and Hellemans, 2018). But this stands in contrast to the well-documented long-lasting effects of social contagion and mental disorders. Hill and colleagues (2010) showed that depressive symptoms acquired through social contagion lasted for, on average, five years until individuals finally recovered. Clinical psychology supports that, once acquired, symptoms of depression (Mueller et al., 1999), anxiety (Bruce et al., 2005), and stress-related disorders (Harkness et al., 2014) show high stability over time. Even after successful psychological therapy, the level of critical symptoms persists compared with healthy control groups and clinical norms (e.g., Vyas, Pillai, and Chattarji, 2004; Evans et al., 2008; Richards, 2011). In addition, organizational newcomers often experience an initial increase in psychological problems after entering a new organization (Dunford et al., 2012) because joining a new organization is a comprehensive transition process involving adjustment to new role demands, stress, uncertainty, and anxiety (Saks, 1994; Allen, McManus, and Russell, 1999; Bravo et al., 2003). We thus assume that similar to the level of job satisfaction, which remains remarkably stable even if the individual changes jobs or occupations (Judge and Larsen, 2001; Zhou et al., 2017), mental disorders can carry into the new job, with detrimental consequences for the hiring organization.

Second, to lead to new chains of "infections" in the workforce of a hiring organization, symptoms of mental disorders need to be pervasive, such that one single infected individual entering a new environment should have a powerful impact on many other individuals in that environment. Expanding the prior finding that dysfunctional influences can spill over from organizations to newcomers (e.g., Liu et al., 2015), we suggest that dysfunctional influences may also spill over in the other direction, from newcomers to organizations. Social contagion effects can pervade large social networks (Rosenquist, Fowler, and Christakis, 2011; Kramer, Guillory, and Hancock, 2014) and extend over multiple points of contact ("friend of a friend of a friend"; Cacioppo, Fowler, and Christakis, 2009; Bastiampillai, Allison, and Chan, 2013). That is, an individual initially might transfer a negative emotion, cognition, or behavior to only one coworker in a dyadic exchange, but secondary or tertiary sharing allows that initial coworker to spread the contagion effects to other individuals in the organization (Christophe and Rimé, 1997; Rimé, 2009). We suggest that the contagion of depression, anxiety, and stress will be pervasive due to the positive-negative asymmetry ("bad is stronger than good") effect (Baumeister et al., 2001), which holds that individuals respond more strongly to negative than to positive stimuli (Fiske, 1980; Taylor, 1991). Negative aspects thus have a stronger effect on individuals' moods (Peeters and Czapinski, 1990), and negative human expressions - such as those related to depression or anxiety-are more contagious than positive expressions (Hatfield, Cacioppo, and Rapson, 1994; Waters, West, and Mendes, 2014; Kelly, lannone, and McCarty, 2016). The dominance in contagion of negative affective states has been demonstrated in the work context, where negative moods are transmitted more easily than positive moods (Sy and Choi, 2013; Barsade, Coutifaris, and Pillemer, 2018). Even one "toxic" member may be enough to affect all other members 
of a work group (Barsade, 2002; Felps, Mitchell, and Byington, 2006). In addition, research on teams supports the idea that members of an existing established group can be affected strongly by the inclusion of a single new member. This is because the entry of a new group member is a disruptive event that initially causes imbalance and instability in the group (Summers, Humphrey, and Ferris, 2012). Using the disease epidemiology metaphor, the existing workforce would be vulnerable (Bonita, Beaglehole, and Kjellström, 2006), which increases the likelihood of mental disorder contagion.

We thus expect depression, anxiety, and stress-related disorders to be longlasting and pervasive enough that an "infective" newcomer can initiate an increase of these mental disorder diagnoses in a hiring organization. This is in line with findings that-even though the development of mental disorders depends on a variety of factors, including genetic vulnerability-social relationships and especially social contagion effects can have a powerful longterm impact on individuals' mental health (Hill et al., 2010; Haeffel and Hames, 2014; Santini et al., 2015). To use the infectious disease epidemiology terminology, we thus suggest that hiring newcomers with mental disorders will lead to increased incidence of this mental disorder within that new susceptible population. Incidence indicates the number of newly infected individuals in a given time period in a specified population and thus the risk of susceptible individuals being affected (Bonita, Beaglehole, and Kjellström, 2006). Consequently, we hypothesize that:

Hypothesis $1(\mathrm{H} 1)$. Hiring newcomers with diagnosed (a) depression, (b) anxiety, or (c) stress-related disorders will increase the incidence of these mental disorders in the workforces of the hiring organizations.

\section{Contagion effects through mobility of individuals leaving unhealthy}

organizations. Following the idea that organizations can be overall unhealthy or healthy, there might also be an effect from hiring a newcomer leaving a particularly "infectious" environment. We suggest that organizations will experience an increased incidence of depression, anxiety, and stress in their workforce after hiring from an unhealthy organization with a high prevalence of mental disorders. This is because hiring from an unhealthy organization might increase the risk of hiring newcomers with (a) full-blown and formally diagnosed mental disorders or (b) not (or not yet) formally diagnosed mental disorders with full-blown or subclinical symptoms. Notably, we suggest that both types of newcomers will show enhanced mental disorder-related symptoms (emotion, cognition, and behavior) and thereby may initiate a new chain of infections in the new organization. In the most straightforward case, the high prevalence of mental disorders in an unhealthy organization makes it more likely that newcomers leaving this "infectious" environment will have diagnosed full-blown depression, anxiety, or stress-related disorders, leading to the contagion effects hypothesized above.

It is also likely that newcomers leaving unhealthy organizations may have full-blown mental disorders that are not (yet) formally diagnosed. In fact, undiagnosed cases play a major role in the discussion of mental disorders (e.g., Joiner, Buchman-Schmitt, and Chu, 2017). While the number of individuals with mental disorder diagnoses is increasing rapidly (Gyllenberg et al., 2018), 
scholars suspect that the actual number of people with symptoms of mental disorders might be much higher (Schaefer et al., 2017). The considerable number of existing but undiagnosed mental disorders can be explained by the fact that many people with mental disorders do not seek treatment (Schaefer et al., 2017) and thus do not receive formal diagnoses. Conservative estimates are that only half of those who need treatment for mental disorders receive treatment (Alonso et al., 2007; Andrade et al., 2014). Moreover, those who seek treatment often do so after a substantial delay of several years (Wang et al., 2005). An impactful reason for these effects is the social stigma associated with mental problems (Schomerus and Angermeyer, 2008; Wiklund et al., 2018). Especially individuals in employment relationships may avoid seeking treatment for existing mental disorders due to fear of losing their jobs and the public image that associates mental disorders with being untrustworthy or having poor social skills (Ten Have et al., 2010).

Moreover, some newcomers might have acquired mental disorder symptoms in unhealthy organizations that do not (yet) meet the full criteria for a formal diagnosis, i.e., subclinical symptoms. Since mental disorder diagnosis is a binary (yes/no) assessment, the probability of being diagnosed depends on the severity of symptoms. But undiagnosed individuals can also have various symptoms of mental disorders that vary on a broad continuum (Ayuso-Mateos et al., 2010; Angermeyer et al., 2015; Tebeka et al., 2018) and might therefore also be contagious. This is in line with infectious disease epidemiology showing that individuals who have not been recorded as infective cases but who show subclinical signs or symptoms of that disease can be the source of further infection (Glass, Becker, and Clements, 2007; Straif-Bourgeois, Ratard, and Kretzschmar, 2014). Individuals with subclinical or subthreshold mental disorder symptoms might have mild symptoms that are early signs of imminent disorder, signs of a residual disorder, or only temporarily occurring (Fava, 1999; Gajewski et al., 2017).

Even if newcomers have not (yet) been formally diagnosed with mental disorders, their symptomatology might reflect the emotions, cognitions, and behaviors characteristic of certain mental disorders that they have adapted from their coworkers in the previous organization (Beyer and Hannah, 2002; Carr et al., 2006). By continuing to display these emotions, cognitions, and behaviors in the new organization, they will expose their new coworkers to apparent signs of mental disorders, thereby increasing the likelihood of contagion. The idea that an "infectious" previous work environment can have a prolonged impact on the employee's behavior even in a new environment has also been discussed in the context of organizational imprinting (McEvily, Jaffee, and Tortoriello, 2011). This research shows that work experience in a specific organizational environment in the past can have a long-lasting impact on the individual's subsequent behaviors, habits, and routines (Tilcsik, 2014) in another organizational context. In the context of employee mobility, imprinting implies that "no newcomer is an entirely blank slate" (Tilcsik, 2014: 644). As a practical example, some recruiters report being cautious about hiring employees from "infamous" competitors, because they might bring in "unhealthy" behavior learned in this prior organizational environment (Kantor and Streitfeld, 2015). Moreover, since employees tend to maintain their social ties after leaving an organization (Agrawal, Cockburn, and McHale, 2006; Corredoira and Rosenkopf, 2010), they will likely remain in contact with their 
former-infective-colleagues. We thus expect the incidence of mental disorders in the hiring organization to increase when hiring newcomers leaving unhealthy organizations regardless of a mental disorder diagnosis or not. We hypothesize that:

Hypothesis $2(\mathrm{H} 2)$. Hiring newcomers leaving unhealthy organizations with a high prevalence of depression, anxiety, or stress-related disorders will increase the incidence of depression, anxiety, and stress-related disorders in the workforces of the hiring organizations. The incidence will be increased both by (a) hiring newcomers with mental disorder diagnoses and (b) hiring newcomers without mental disorder diagnoses leaving unhealthy organizations.

The moderating role of managerial position. We suggest further that the strength of the above-noted contagion effects will depend on the status or position of the newcomer in the hiring organization. For two main reasons we expect contagion effects to be stronger if the newcomer is hired to fill a managerial (i.e., leadership) position. First, leadership responsibilities imply frequent social interactions with followers (Graen and Uhl-Bien, 1995) and thus more frequent opportunities for managers with a mental disorder background-hired from an unhealthy organization and/or diagnosed with a mental disorder themselves - to interact closely with other individuals in the hiring organization. In turn, this provides more opportunities for the symptoms related to mental disorders to be transferred (Sy, Côté, and Saavedra, 2005; Köppe, Kammerhoff, and Schütz, 2018).

Second, status differences are an important factor in social contagion. Since subordinates tend to be dependent on their leaders, they will have a stronger awareness of these leaders' emotions, cognitions, and behaviors (Sy and Choi, 2013). Consequently, subordinates are more likely to "catch" the moods of their leaders than vice versa (Sy, Côté, and Saavedra, 2005; Hobfoll et al., 2018) and are more susceptible to mimic symptoms of a mental disorder displayed by a new manager than by a new coworker:

Hypothesis 3 (H3). The contagion effects of depression, anxiety, and stress-related disorders will be stronger if the newcomer is hired for a managerial position.

\section{METHOD}

\section{Data and Sample}

We based our study on an extensive longitudinal dataset comprising approximately a quarter of the total employees in private enterprises in the Danish labor market. Our data were gathered from the Integrated Labor Market database (IDA) supplied by Statistics Denmark, which provides information on job type, salary, education level, employer relation, and level of managerial responsibility. We complemented these data with firm-level register data on firm accounts, location, sales, and export activity. The organizations and citizens included in these databases are identified respectively by unique firm identifiers, CVR, and unique person identifiers, CPR. ${ }^{3}$ This allowed us to (anonymously) match each individual employee with the organization in which

3 The data were anonymized by Statistics Denmark prior to our access. 
they are currently or were previously employed. It allowed a detailed insight into the activities of both individuals and organizations over time, including job changes across organizations.

To observe the health of the individuals in our sample-including potential occurrence of mental disorders-we combined our data with the hospital diagnostics database (SYIN) and a general practitioner catalog (SSSY/SYSI) during the period 1996 to 2015. SYIN contains detailed information on all hospital visits made in Denmark using the national public health system, registering the relevant medical action taken using the International Classification of Diseases (ICD-10), patient identifier (CPR), location, and time of treatment. SSSY and SYSI records the diagnoses and treatment by general and specialist doctors. These data provide detailed insight into both the individual's past medical history and the potential health effects caused by labor market interaction.

The data collection resulted in more than 250,000 unique individuals observed between 1996 and 2015 who were employed in about 24,000 unique private enterprises over the same time period. To remove home offices and cottage industries, we restricted our sample to organizations with 10 or more employees. Our data were organized in an unbalanced panel since both individuals and organizations entered and left the data during the period of study. We reserved the first five years of our sample for pre-estimation of the individual's medical history and the organization's history of prior mental disorders. ${ }^{4}$ This period was chosen to allow sufficient time to register frequent medical or mental health-related issues (Hakanen, Schaufeli, and Ahola, 2008). We excluded the final three years from the analysis to serve as the observation period for the dependent variablethat is, calculation of the three-year incidence rate, which is our main dependent variable. Our final sample contains 17,658 unique organizations observed across 12 years, resulting in 144,117 firm-year observations.

\section{Measures}

Dependent variable. Incidence rate of mental disorders in the hiring organization. Our dependent variable measures the ratio of the hiring organization's employees with mental disorders in the time period following a new hire. This variable is constructed as the incidence rate (Bonita, Beaglehole, and Kjellström, 2006) and calculated as the number of new mental disorder cases per time window divided by the total number of exposed individuals at the beginning of the time window $\left(t_{0}\right)$. Following the common approach of calculating incidence rates as percentages (e.g., Wesselhoeft et al., 2015), we multiplied the value by 100 . We defined our time window as the three years following a new observed hire $(t+3)$ (Hakanen, Schaufeli, and Ahola, 2008) and tested other time windows as robustness checks.

Independent variables. Hiring newcomers with mental disorder diagnoses. We examined the number of individuals hired with clinical diagnoses of depression, anxiety, or stress-related disorders. We defined an individual as having a mental disorder if they received the related diagnosis in the year

\footnotetext{
${ }^{4}$ As explained in more detail in the description of our control variables, we controlled for the individuals' general medical history and for potential prior incidents of mental disorders in the previous five years.
} 
prior to the job change (hiring by the organization). ${ }^{\mathbf{5}}$ We examined three clusters of mental disorders based on the following ICD-10 codes: depressive disorders (major depression, F32.xx), anxiety-related disorders (anxiety disorder, F41.9), and stress-related disorders (reactions to severe stress and adjustment disorder, F43.20; other reaction to severe stress, F43.8; work-related neurasthenia, F48.0). We extracted these ICD-10 codes for the individuals in our sample using the medical records databases, which allowed exact identification of individuals to a relevant diagnosis.

Hiring newcomers without mental disorder diagnoses. Since we proposed that newcomers without a mental disorder would also be contagious when leaving unhealthy organizations, we also examined the number of individuals hired with no prior diagnosis of depression, anxiety, or stress-related disorders in the previous year (constructed analogous to the "hiring newcomers with mental disorder diagnoses" variable).

Hiring newcomers leaving unhealthy organizations. We define an unhealthy organization as one with an above-normal level of employees diagnosed with depression, anxiety, and stress-related disorders in the year of observation. This is measured as the prevalence rate of these mental disorders across the organization, with the upper quartile of the organizations defined as belonging to the "unhealthy" category. ${ }^{\mathbf{6}}$ The prevalence rate is calculated as the number of mental disorder cases per time window in the leaving organization divided by the number of mental disorder cases at the beginning of the time window (Bonita, Beaglehole, and Kjellström, 2006).

Managerial position. We measured whether the new employee was hired to fill a managerial position. The variable takes the value of 1 if the new employee filled a managerial position and 0 if not.

Control variables. The transmission of mental disorders to the hiring organization might also be affected by factors other than the hypothesized contagion effects. To account for that possibility, we controlled for various individual and firm characteristics and for time effects.

Individual characteristics. Some individuals may have a higher likelihood of carrying, and therefore transmitting, mental disorders. Prior evidence has shown that occurrence and severity of mental disorders are linked to gender (Seedat et al., 2009), age (Kessler et al., 2007), occupation (Stansfeld et al., 2011), education, and income (Fryers, Melzer, and Jenkins, 2003). Therefore, we controlled for gender (male coded as 0 and female coded as 1) of the hired individual and age (in years) at the time of the job change. Occupation is classified according to the major International Standard Classification of Occupations (ISCO) groups, which include ten distinct occupational groups. The variable is categorized according to the ISCO primary classifications as follows: managers

\footnotetext{
$\mathbf{5}$ The employer-employee relation is updated annually on November 1; hence we could not determine whether the job change took place prior to or following a mental disorder diagnosis. To reduce the likelihood of observing false positives, we recorded only diagnoses made in the year prior to rather than the year of the job change.

6 This categorization aligns with our theoretical arguments in which we distinguish between "healthy" and "unhealthy" organizations. It additionally echoes the empirically found distribution of mental disorder prevalence rates across the Danish firms observed. We have also tested our models using the exact prevalence instead of the categorical variable and found the results to be highly similar in terms of the strength and significance of effects.
} 
(1), professionals (2), technicians and associate professionals (3), clerical support workers (4), service and sales workers (5), skilled agricultural, forestry, and fishery workers (6), craft and related trade workers (7), plant and machine operators and assemblers (8), elementary occupations (9), and armed forces (10). Education level is measured as the highest level of education completed at the time of job change according to the International Standard Classification of Education as follows: primary (1), lower secondary (2), upper secondary (3), post-secondary non-tertiary (4), short-cycle tertiary (5), bachelors (6), masters (7), and doctoral (8). Personal income is calculated as the logarithmic value of the individual's annual pre-tax income (in DKK).

Moreover, it is possible that job changers with longer medical historiesboth relating to psychological and physical health-might show more severe symptomatology (De Girolamo et al., 2012) and thus might be more likely to transmit mental disorders. We thus controlled for job changers'medical history. We measured prior medical history as a normalized Herfindahl index of the different types of diagnoses received in the previous five years and the frequency of treatment for these conditions. An individual might have a high number of diagnoses belonging to a single disease classification or multiple single diagnoses of different diseases. Compared with simple counting of the number of unique diagnoses or total number of diagnoses, this definition of medical history ensures that neither is particularly favored. Additionally, we controlled for prior mental disorder incidents to capture whether individuals had further mental disorder diagnoses in the past five years. Finally, in line with imprinting theory (e.g., Tilcsik, 2014), the timespan spent in (un)healthy organizations could affect the likelihood of developing and consequently spreading mental disorders. We thus controlled for job changers' tenure in the previous organization measured as years employed.

Firm characteristics. The characteristics of the hiring firm might make it more or less likely that mental disorders introduced by hiring newcomers spread across the workforce. One such characteristic is firm size. On the one hand, newcomers to large firms may be embedded in larger internal networks (Collins and Clark, 2003), which might facilitate more collaboration among employees and thus more opportunities for contagion. On the other hand, smaller firms with flatter hierarchies (Rajan and Wulf, 2006) might facilitate mental disorder contagion. To account for these effects, we controlled for firm size measured as the logarithm of the number of the firm's employees.

Moreover, since industries differ in the severity of their working conditions, in the frequency of teamwork and social interaction among employees, and possibly also in the overall prevalence of mental health issues, the industry of the hiring firm might play a role in the occurrence of contagion effects (Devine et al., 1999; Nahrgang, Morgeson, and Hofmann, 2011). We controlled for industry using the two-digit NACE codes split into a number of firm dummies for manufacturing, construction, trade/transport, information and communications technology (ICT), financial, and other. We further controlled for mental disorder prevalence (i.e., the base rate of mental disorders) in the hiring organization at the time of the job change as the effects might also depend on whether newcomers enter a previously healthy or unhealthy hiring organization. For instance, unhealthy organizations might be more inclined to hire from other unhealthy organizations (McCulloch and Turban, 2007), thus further reinforcing the risk of mental disorder increase. 
Time effects. Our study covers a long time period during which both overall prevalence of mental disorders (Weissman et al., 2017) and attitudes to mental disorders in society (Mirnezami, Jacobsson, and Edin-Liljegren, 2016) might have changed. To account for the possible confounding effects of time, we included the year of job change as a control variable.

\section{Analysis}

Since our dependent variable incidence rate is an interval variable, we employed ordinary least squares (OLS) regression, which can be specified as follows:

$$
E\left(\text { incidencerate }_{i}\right)=\beta_{0}+\beta_{1} X_{i}+u_{i}
$$

where $\beta_{0}$ is the intercept coefficient, $\beta_{1} X_{i}$ is the slope coefficient, and $u_{i}$ is the residual. This model is appropriate since our dependent variable does not follow a normal distribution; it is highly skewed due to generally low rates of mental disorder incidence in the population. To ensure that the basic assumptions of the model are not violated, we used the Shapiro-Wilk test (Greene, 2011) to test for normality and the Breusch-Pagan test (Wooldridge, 2004) to test for heteroscedasticity. The standard errors are normally distributed, indicating that our data do not suffer from normality issues; however, our tests suggest that heteroscedasticity might be an issue. We accounted for this by employing Hubert-White sandwich estimators and using robust standard errors in our models.

\section{RESULTS}

Table 1 presents the descriptive statistics and the pairwise correlations between our variables. Tables 2-5 present the results of our OLS specifications. Table 2 presents models combining individuals diagnosed with depression, anxiety, and stress-related mental disorders into one dependent variable. This provides an overview of the general effect. The results for each mental disorder are presented in Tables 3, 4, and 5, for depression, anxiety, and stress-related mental disorders, respectively.

Model 1 in Table 2 is a baseline model containing only the control variables. This indicates the general antecedents of an increased incidence rate within the organization. The model shows a significant link between prior prevalence and later incidence of mental disorders, indicating that already unhealthy hiring organizations at the time of the hire tend to have a higher increase in mental disorders in the following three years. Moreover, we observed a significant effect of firm size, indicating that the incidence of mental disorders is higher in larger firms. Models 2-6 test our hypotheses. H1 suggests that hiring newcomers diagnosed with one of three mental disorders will increase organizations' mental disorders incidence rate for the respective mental disorder. Model 2 shows that the coefficient of hiring newcomers with mental disorder diagnoses is 0.812 ( $p<.001$ ), which lends support to H1. Hiring individuals with recent mental disorder diagnoses raises the incidence rate of mental disorders in the hiring organization significantly. We calculated the effect size using Hedges' $g$ and found that hiring newcomers with mental 
Table 1. Descriptive Statistics and Correlations among Study Variables

\begin{tabular}{|c|c|c|c|c|c|c|c|c|c|c|c|}
\hline & Mean & S.D. & 1 & 2 & 3 & 4 & 5 & 6 & 7 & 8 & 9 \\
\hline $\begin{array}{l}\text { 1. Incidence rate of mental } \\
\text { disorders (hiring } \\
\text { organization) }\end{array}$ & .103 & .8234 & 1 & & & & & & & & \\
\hline $\begin{array}{l}\text { 2. Hiring newcomers with } \\
\text { mental disorder } \\
\text { diagnoses }\end{array}$ & .233 & 2.334 & .0907 & 1 & & & & & & & \\
\hline $\begin{array}{l}\text { 3. Hiring newcomers } \\
\text { without mental disorder } \\
\text { diagnoses }\end{array}$ & 1.273 & 4.998 & .0775 & .2370 & 1 & & & & & & \\
\hline $\begin{array}{l}\text { 4. Hiring newcomers } \\
\text { leaving unhealthy } \\
\text { organizations }\end{array}$ & .098 & .483 & -.0163 & .3691 & .2297 & 1 & & & & & \\
\hline $\begin{array}{l}\text { 5. Mental disorder } \\
\text { prevalence in the hiring } \\
\text { organization }\end{array}$ & .553 & 1.676 & .3577 & -.0190 & -.0025 & -.0671 & 1 & & & & \\
\hline 6. Firm size & 2.967 & .646 & .0429 & .0758 & -.0338 & -.0692 & .1627 & 1 & & & \\
\hline 7. Managerial position & .074 & .098 & -.0703 & .1172 & .1485 & -.1024 & .1004 & -.1705 & 1 & & \\
\hline 8. Education & 3.662 & 1.83 & .1235 & -.0550 & .0344 & .1223 & -.1043 & -.2114 & -.0320 & 1 & \\
\hline 9. Personal income & 2.029 & .991 & -.0227 & -.0120 & -.0946 & -.0564 & -.0264 & -.0558 & .0124 & .1297 & 1 \\
\hline 10. Gender & 0.266 & .442 & -.0035 & -.0087 & -.0671 & -.1499 & -.0808 & -.0609 & -.0139 & .0631 & -.0300 \\
\hline 11. Age & 42.549 & 12.663 & -.0118 & -.1370 & -.0122 & .3211 & -.1370 & .0470 & -.1554 & .0119 & -.0406 \\
\hline 12. Occupation & 4.155 & 3.092 & .1086 & .0261 & .0321 & -.3771 & -.1463 & -.4489 & .0881 & -.0984 & .0872 \\
\hline 13. Medical history & .102 & .254 & -.0014 & -.0028 & -.0560 & -.0145 & -.0095 & -.0085 & -.0963 & .0874 & -.0160 \\
\hline $\begin{array}{l}\text { 14. Prior mental disorder } \\
\text { incident }\end{array}$ & .032 & .014 & .0034 & -.0054 & .0924 & -.0119 & .0241 & -.1343 & -.0180 & .1002 & .0169 \\
\hline 15. Year of job change & 8.342 & 1.017 & -.0600 & -.1136 & .1033 & -.0979 & .0349 & -.0041 & -.1002 & -.1136 & -.0495 \\
\hline \multirow[t]{2}{*}{ 16. Tenure } & 4.712 & 3.804 & .0034 & .0394 & .0560 & -.0215 & -.0621 & .0263 & -.0340 & .0095 & .0228 \\
\hline & & 10 & & 11 & 12 & & 13 & \multicolumn{2}{|c|}{14} & 15 & 16 \\
\hline \multicolumn{2}{|l|}{ 10. Gender } & 1 & & & & & & & & & \\
\hline \multicolumn{2}{|l|}{ 11. Age } & -.0102 & & 1 & & & & & & & \\
\hline \multicolumn{2}{|l|}{ 12. Occupation } & .1838 & & 1289 & 1 & & & & & & \\
\hline \multicolumn{2}{|c|}{ 13. Medical history } & .3550 & & 2367 & .0108 & & 1 & & & & \\
\hline \multicolumn{2}{|c|}{ 14. Prior mental disorder incident } & .1578 & & 0070 & .0813 & & -.0019 & & 1 & & \\
\hline \multicolumn{2}{|c|}{ 15. Year of job change } & -.0671 & & 0624 & -.0556 & & .1724 & -.38 & 871 & 1 & \\
\hline \multicolumn{2}{|l|}{ 16. Tenure } & .0771 & & 1953 & -.1016 & & -.0045 & -.14 & 499 & .0004 & 1 \\
\hline
\end{tabular}

disorder diagnoses explained 6.32 percent of the variation in the incidence rate of the hiring organization $\left(\omega^{2}=0.0632 ; \mathrm{Cl}[0.0531 ; 0.0652]\right) .{ }^{7}$ Examining model 2 for the three types of mental disorders separately (Tables 3, 4, and 5), we find a positive, significant effect for hiring individuals diagnosed with depression $\left(\beta_{i}=1.001 ; p<.001, \omega^{2}=0.0639 ; \mathrm{Cl}[0.0588 ; 0.0702]\right)$, anxiety $\left(\beta_{\mathrm{i}}=\right.$ $\left.1.606 ; p<.001, \omega^{2}=0.0781 ; \mathrm{Cl}[0.0663 ; 0.0822]\right)$, and stress-related disorders

\footnotetext{
7 The effect sizes are comparable with those found in similar studies that examine changes in multilevel data with low base rate medical diagnoses (Dahl, Dezső, and Ross, 2012; Dahl and Pierce, 2020a) and thus should not be compared with effect sizes in experimental data. It is important to emphasize the severity of small (relative) increases in diagnosed mental health problems, as they result in high numbers of actual cases, which in turn affect an even higher number of other coworkers (see Dahl and Pierce, 2020b for a detailed explanation).
} 
Table 2. Hypotheses Tests: OLS with Robust Standard Errors. Dependent Variable: Mental Disorders (Combined) Incidence Rate in $t+3^{*}$

\begin{tabular}{|c|c|c|c|c|c|c|}
\hline & Model 1 & Model 2 & Model 3 & Model 4 & Model 5 & Model 6 \\
\hline \multirow[t]{2}{*}{ Hiring newcomers with mental disorder diagnoses } & & $.812^{\bullet \bullet \bullet}$ & $.824^{\bullet \bullet \bullet}$ & $.949 \bullet \bullet$ & $.726^{\bullet \bullet \bullet}$ & $.824^{\bullet \bullet}$ \\
\hline & & {$[.011]$} & {$[.011]$} & [.113] & {$[.019]$} & {$[.011]$} \\
\hline \multirow[t]{2}{*}{ Hiring newcomers without mental disorder diagnoses } & & .003 & .003 & .003 & .004 & .003 \\
\hline & & [.023] & {$[.002]$} & [.002] & {$[.025]$} & {$[.002]$} \\
\hline \multirow[t]{2}{*}{ Hiring newcomers leaving unhealthy organizations } & & & $1.029^{\bullet \bullet \bullet}$ & $.008 \bullet \bullet$ & $.313^{\bullet \bullet}$ & $.104^{\cdots}$ \\
\hline & & & {$[.002]$} & {$[.002]$} & {$[.025]$} & {$[.003]$} \\
\hline \multirow{2}{*}{$\begin{array}{l}\text { Hiring newcomers with mental disorder diagnoses } \times \\
\text { Hiring newcomers leaving unhealthy organizations }\end{array}$} & & & & $2.219^{\bullet \bullet \bullet}$ & & $1.374^{\bullet \bullet \bullet}$ \\
\hline & & & & {$[.012]$} & & [.704] \\
\hline \multirow{2}{*}{$\begin{array}{l}\text { Hiring newcomers without mental disorder diagnoses } \times \\
\text { Hiring newcomers leaving unhealthy organizations }\end{array}$} & & & & $1.401 \bullet \bullet$ & & $.766^{\bullet \bullet}$ \\
\hline & & & & {$[.066]$} & & {$[.021]$} \\
\hline \multirow[t]{2}{*}{ Managerial position } & & $1.050^{\bullet \bullet \bullet}$ & $1.052^{\bullet \bullet \bullet}$ & $1.051^{\bullet \bullet \bullet}$ & $.215^{\bullet \bullet \bullet}$ & $.218^{\bullet \bullet}$ \\
\hline & & {$[.050]$} & {$[.053]$} & {$[.051]$} & {$[.003]$} & {$[.004]$} \\
\hline \multirow{2}{*}{$\begin{array}{l}\text { Managerial position } \times \text { Hiring newcomers with mental } \\
\text { disorder diagnoses }\end{array}$} & & & & & $2.572^{\bullet \bullet}$ & $2.194^{\bullet \bullet}$ \\
\hline & & & & & [.128] & {$[.015]$} \\
\hline \multirow{2}{*}{$\begin{array}{l}\text { Managerial position } \times \text { Hiring newcomers without mental } \\
\text { disorder diagnoses }\end{array}$} & & & & & $1.874^{\bullet \bullet}$ & $1.701^{\cdots} \bullet$ \\
\hline & & & & & {$[.077]$} & [.373] \\
\hline \multirow{2}{*}{$\begin{array}{l}\text { Managerial position } \times \text { Hiring newcomers leaving } \\
\text { unhealthy organizations }\end{array}$} & & & & & $1.109 \bullet \bullet$ & $.934^{\cdots \bullet}$ \\
\hline & & & & & {$[.014]$} & {$[.010]$} \\
\hline \multirow[t]{2}{*}{ Tenure } & .030 & .023 & .052 & .042 & .063 & .044 \\
\hline & {$[.12]$} & {$[.054]$} & {$[.077]$} & {$[.078]$} & {$[.082]$} & {$[.080]$} \\
\hline \multirow{2}{*}{$\begin{array}{l}\text { Tenure } \times \text { Hiring newcomers leaving unhealthy } \\
\text { organizations }\end{array}$} & & & & & $.028^{\bullet \bullet}$ & $.036^{\bullet}$ \\
\hline & & & & & {$[.002]$} & {$[.022]$} \\
\hline \multirow[t]{2}{*}{ Prior mental disorder incident } & .002 & .002 & .002 & .002 & .002 & .002 \\
\hline & {$[.010]$} & {$[.009]$} & {$[.009]$} & {$[.009]$} & {$[.010]$} & {$[.009]$} \\
\hline \multirow[t]{2}{*}{ Medical history } & $.000^{\circ \bullet}$ & $.000^{\circ \bullet}$ & $.001^{\bullet \bullet}$ & .001 & $.000^{\bullet \bullet}$ & $.000^{\circ}$ \\
\hline & {$[.000]$} & {$[.000]$} & {$[.000]$} & {$[.001]$} & {$[.000]$} & {$[.000]$} \\
\hline \multirow[t]{2}{*}{ Education } & $-.001^{\bullet \bullet}$ & $-.000^{\bullet}$ & $-.001^{\bullet}$ & $-.001^{\bullet}$ & $-.001^{\bullet \bullet}$ & $-.001^{\bullet}$ \\
\hline & {$[.000]$} & {$[.000]$} & {$[.000]$} & {$[.000]$} & {$[.000]$} & {$[.000]$} \\
\hline \multirow[t]{2}{*}{ Age } & .000 & .000 & .000 & .000 & .000 & .000 \\
\hline & {$[.000]$} & {$[.000]$} & {$[.000]$} & {$[.000]$} & {$[.000]$} & {$[.000]$} \\
\hline \multirow[t]{2}{*}{ Gender } & .000 & .000 & .000 & .000 & .000 & .000 \\
\hline & {$[.000]$} & {$[.000]$} & {$[.001]$} & {$[.000]$} & {$[.000]$} & {$[.000]$} \\
\hline \multirow[t]{2}{*}{ Personal income } & $-.001^{\bullet \bullet}$ & $-.004^{\bullet \bullet \bullet}$ & $-.001^{\bullet \bullet \bullet}$ & $-.001^{\bullet}$ & $-.005^{\bullet \bullet \bullet}$ & $-.002^{\bullet \bullet}$ \\
\hline & {$[.001]$} & {$[.000]$} & {$[.000]$} & {$[.000]$} & {$[.001]$} & {$[.000]$} \\
\hline \multirow[t]{2}{*}{ Occupation } & .067 & $.007^{\bullet \bullet \bullet}$ & $.007^{\bullet \bullet \bullet}$ & $.071^{\bullet \bullet \bullet}$ & $.070^{\bullet \bullet \bullet}$ & $.041^{\cdots}$ \\
\hline & [.003] & {$[.000]$} & {$[.000]$} & {$[.000]$} & {$[.000]$} & {$[.001]$} \\
\hline \multirow[t]{2}{*}{ Mental disorder prevalence in the hiring organization } & $.047^{\bullet \bullet \bullet}$ & $.044^{\bullet \bullet}$ & $.042^{\bullet \bullet \bullet}$ & $.043^{\bullet \bullet \bullet}$ & $.045^{\bullet \bullet}$ & $.044^{\cdots}$ \\
\hline & {$[.001]$} & {$[.001]$} & {$[.001]$} & {$[.001]$} & {$[.001]$} & {$[.001]$} \\
\hline \multirow[t]{2}{*}{ Firm size } & $.006^{\bullet \bullet \bullet}$ & .005 & $-.005^{\bullet \bullet}$ & $-.006^{\bullet \bullet}$ & $-.034^{\bullet \bullet \bullet}$ & $-.037^{\bullet \bullet}$ \\
\hline & {$[.001]$} & {$[.009]$} & {$[.001]$} & {$[.001]$} & {$[.001]$} & {$[.001]$} \\
\hline Year of job change & -.047 & -.046 & .049 & -.021 & -.006 & -.021 \\
\hline & [.073] & [.068] & [.045] & [.025] & [.019] & [.025] \\
\hline Industry dummies & Included & Included & Included & Included & Included & Included \\
\hline Constant & $-1.093^{\bullet \bullet}$ & $-1.093 \bullet \bullet$ & $-1.093^{\bullet \bullet}$ & $-1.358 \cdots$ & $-1.098 \bullet \bullet$ & $-1.467^{\bullet \bullet}$ \\
\hline & [.098] & [.098] & [.098] & [.154] & [.098] & [.117] \\
\hline Number of observations & 144,117 & 144,117 & 144,117 & 144,117 & 144,117 & 144,117 \\
\hline R-squared & .1245 & .2096 & .2153 & .2449 & .2721 & .2694 \\
\hline F test & $32.221^{\bullet \bullet}$ & $36.117^{\bullet \bullet \bullet}$ & $35.869^{\bullet \bullet \bullet}$ & $32.279^{\bullet \bullet}$ & $33.232^{\bullet \bullet \bullet}$ & $32.325^{\bullet \bullet}$ \\
\hline$\Delta \mathrm{R}$-squared & - & .0851 & .0057 & .0296 & .0272 & .0272 \\
\hline$\Delta \mathrm{F}$ test & - & $20.23^{\bullet \bullet}$ & $32.18^{\bullet \bullet \bullet}$ & $52.50^{\bullet \bullet \bullet}$ & $68.07^{\bullet \bullet}$ & $68.07^{\bullet \bullet \bullet}$ \\
\hline
\end{tabular}

$\bullet p<.05 ; \bullet p<.01 ; \cdots p<.001$.

* For the sake of brevity, the effects of the single industry dummies are not displayed in this table. Detailed results are available from the authors upon request.

$\left(\beta_{i}=1.243 ; p<.001, \omega^{2}=0.0701 ; \mathrm{Cl}[0.0647 ; 0.0771]\right)$ on the incidence of the respective mental disorders in the workforce of the hiring firm, further

supporting $\mathrm{H} 1$.

$\mathrm{H} 2$ predicts that hiring newcomers from an unhealthy organization (i.e., with a high prevalence of mental disorders) will lead to a higher incidence rate in the hiring organization, independent of whether newcomers have formal mental 
Table 3. Hypotheses Tests: OLS with Robust Standard Errors. Dependent Variable: Depression Incidence Rate in $t+3$

\begin{tabular}{|c|c|c|c|c|}
\hline & Model 1 & Model 2 & Model 3 & Model 4 \\
\hline \multirow[t]{2}{*}{ Hiring newcomers with mental disorder diagnoses } & & $1.001^{\bullet \bullet \bullet}$ & $1.109^{\bullet \bullet}$ & $1.174^{\bullet \bullet \bullet}$ \\
\hline & & {$[.014]$} & {$[.014]$} & {$[.017]$} \\
\hline \multirow[t]{2}{*}{ Hiring newcomers without mental disorder diagnoses } & & -.245 & -.241 & $-.327^{\bullet}$ \\
\hline & & {$[.168]$} & {$[.168]$} & {$[.185]$} \\
\hline \multirow[t]{2}{*}{ Hiring newcomers leaving unhealthy organizations } & & $.215^{\bullet \bullet \bullet}$ & $.132 \bullet \bullet$ & $.127^{\bullet \bullet \bullet}$ \\
\hline & & {$[.003]$} & {$[.004]$} & {$[.005]$} \\
\hline $\begin{array}{l}\text { Hiring newcomers with mental disorder diagnoses } \times \text { Hiring newcomers leaving } \\
\text { unhealthy organizations }\end{array}$ & & & $\begin{array}{l}.218^{\bullet \bullet \bullet} \\
{[.004]}\end{array}$ & \\
\hline $\begin{array}{l}\text { Hiring newcomers without mental disorder diagnoses } \times \text { Hiring newcomers leaving } \\
\text { unhealthy organizations }\end{array}$ & & & $\begin{array}{l}.468^{\bullet \bullet \bullet} \\
{[.027]}\end{array}$ & \\
\hline \multirow[t]{2}{*}{ Managerial position } & $.663^{\bullet \bullet}$ & $.715^{\bullet \bullet \bullet}$ & $.726^{\bullet \bullet \bullet}$ & $.466^{\bullet \bullet \bullet}$ \\
\hline & {$[.015]$} & {$[.017]$} & {$[.019]$} & {$[.021]$} \\
\hline \multirow[t]{2}{*}{ Managerial position $\times$ Hiring newcomers with mental disorder diagnoses } & & & & $.824^{\bullet \bullet \bullet}$ \\
\hline & & & & {$[.011]$} \\
\hline \multirow[t]{2}{*}{ Managerial position $\times$ Hiring newcomers without mental disorder diagnoses } & & & & $.194^{\bullet \bullet \bullet}$ \\
\hline & & & & {$[.074]$} \\
\hline \multirow[t]{2}{*}{ Managerial position $\times$ Hiring newcomers leaving unhealthy organizations } & & & & $.766^{\bullet \bullet}$ \\
\hline & & & & {$[.021]$} \\
\hline Prior mental disorder incident & $.028^{\bullet \bullet}$ & $.028 \bullet \bullet$ & $.028^{\bullet \bullet}$ & $.028^{\bullet \bullet \bullet}$ \\
\hline \multirow[t]{2}{*}{ Tenure } & .023 & .016 & .030 & .018 \\
\hline & {$[.016]$} & {$[.016]$} & [.023] & {$[.026]$} \\
\hline \multirow[t]{2}{*}{ Medical history } & $.103^{\bullet \bullet}$ & $.094^{\bullet \bullet \bullet ~}$ & $.104^{\bullet \bullet \bullet}$ & $.095^{\bullet \bullet}$ \\
\hline & [.003] & {$[.004]$} & {$[.003]$} & {$[.004]$} \\
\hline \multirow[t]{2}{*}{ Education } & $-.036^{\bullet \bullet \bullet}$ & $-.034^{\bullet \bullet \bullet}$ & $-.037^{\bullet \bullet \bullet}$ & $-.035^{\bullet \bullet \bullet}$ \\
\hline & {$[.001]$} & {$[.001]$} & {$[.001]$} & {$[.001]$} \\
\hline \multirow[t]{2}{*}{ Age } & $.057^{\bullet \bullet \bullet}$ & $.049^{\bullet \bullet \bullet}$ & $.045^{\bullet \bullet \bullet}$ & $.038^{\bullet \bullet \bullet}$ \\
\hline & {$[.006]$} & {$[.006]$} & {$[.007]$} & {$[.008]$} \\
\hline \multirow[t]{2}{*}{ Gender } & .000 & .000 & .000 & .000 \\
\hline & {$[.000]$} & {$[.000]$} & {$[.000]$} & {$[.000]$} \\
\hline \multirow[t]{2}{*}{ Personal income } & $-.005^{\bullet \bullet \bullet}$ & $-.006^{\bullet \bullet \bullet}$ & $-.034^{\bullet \bullet \bullet}$ & $-.037^{\bullet \bullet \bullet}$ \\
\hline & {$[.001]$} & {$[.001]$} & {$[.001]$} & {$[.001]$} \\
\hline \multirow[t]{2}{*}{ Occupation } & $.001^{\bullet \bullet}$ & $.004^{\bullet \bullet \bullet}$ & $.001^{\bullet \bullet \bullet}$ & $.001^{\bullet}$ \\
\hline & [.001] & {$[.000]$} & {$[.000]$} & {$[.000]$} \\
\hline \multirow[t]{2}{*}{ Mental disorder prevalence in the hiring organization } & .067 & $.007^{\bullet \bullet \bullet}$ & $.007^{\bullet \bullet}$ & $.071^{\bullet \bullet}$ \\
\hline & [.003] & {$[.000]$} & {$[.000]$} & {$[.000]$} \\
\hline \multirow[t]{2}{*}{ Firm size } & $-.004^{\bullet \bullet \bullet}$ & $-.005^{\bullet \bullet \bullet}$ & $-.008^{\bullet \bullet \bullet}$ & $-.009^{\bullet \bullet \bullet}$ \\
\hline & {$[.001]$} & {$[.001]$} & {$[.001]$} & {$[.001]$} \\
\hline \multirow[t]{2}{*}{ Year of job change } & $-.239^{\bullet \bullet \bullet}$ & $-.245^{\bullet \bullet}$ & $-.152 \bullet$ & $-.189 \bullet$ \\
\hline & {$[.085]$} & {$[.096]$} & {$[.086]$} & {$[.097]$} \\
\hline Industry dummies & Included & Included & Included & Included \\
\hline \multirow[t]{2}{*}{ Constant } & $1.437^{\bullet \bullet \bullet}$ & $.090^{\bullet \bullet \bullet}$ & $1.467^{\bullet \bullet}$ & $.066^{\bullet \bullet \bullet}$ \\
\hline & [.013] & {$[.016]$} & {$[.017]$} & {$[.020]$} \\
\hline Number of observations & 144,117 & 144,117 & 144,117 & 144,117 \\
\hline R-squared & .276 & .297 & .306 & .304 \\
\hline F test & $25.6646^{\bullet \bullet \bullet}$ & $50.14815^{\bullet \bullet \bullet}$ & $15.53745^{\bullet \bullet \bullet}$ & $31.79568^{\bullet \bullet}$ \\
\hline$\Delta \mathrm{R}$-squared & - & .0057 & .0296 & .0272 \\
\hline$\Delta \mathrm{F}$ test & - & $32.18^{\bullet \bullet \bullet}$ & $52.50^{\bullet \bullet \bullet}$ & $68.07^{\bullet \bullet \bullet}$ \\
\hline
\end{tabular}

disorder diagnoses. Model 3 in Table 2 shows that hiring newcomers leaving unhealthy organizations had an overall significant effect $\left(\beta_{\mathrm{i}}=1.029 ; p<.001\right)$ of increasing the incidence rate of mental disorders in the hiring organization. Model 4 shows that this effect is present for hiring both newcomers with mental disorder diagnoses and newcomers without mental disorder diagnoses. We find a positive and significant effect $\left(\beta_{\mathrm{i}}=2.219 ; p<.001\right)$ of hiring diagnosed newcomers coming from unhealthy organizations (hiring newcomers with mental disorder diagnoses $\times$ hiring newcomers leaving unhealthy organizations). Hiring diagnosed newcomers from unhealthy organizations accounts for 7.38 percent $\left(\omega^{2}=0.0738 ; \mathrm{Cl}[0.0572 ; 0.0771]\right)$ of the variance in the hiring 
Table 4. Hypotheses Tests: OLS with Robust Standard Errors. Dependent Variable: Anxiety Incidence Rate in $\boldsymbol{t + 3}$

\begin{tabular}{|c|c|c|c|c|}
\hline & Model 1 & Model 2 & Model 3 & Model 4 \\
\hline \multirow[t]{2}{*}{ Hiring newcomers with mental disorder diagnoses } & & $1.606^{\bullet \bullet \bullet}$ & $2.194^{\bullet \bullet \bullet}$ & $1.586^{\bullet \bullet \bullet}$ \\
\hline & & [.012] & {$[.015]$} & {$[.016]$} \\
\hline \multirow[t]{2}{*}{ Hiring newcomers without mental disorder diagnoses } & & -.020 & -.021 & -.006 \\
\hline & & [.022] & {$[.025]$} & [.019] \\
\hline \multirow[t]{2}{*}{ Hiring newcomers leaving unhealthy organizations } & & $1.104^{\bullet \bullet \bullet}$ & $1.126^{\bullet \bullet \bullet}$ & $1.475^{\bullet \bullet \bullet}$ \\
\hline & & {$[.010]$} & {$[.086]$} & {$[.075]$} \\
\hline \multirow{2}{*}{$\begin{array}{l}\text { Hiring newcomers with mental disorder diagnoses } \times \text { Hiring newcomers leaving } \\
\text { unhealthy organizations }\end{array}$} & & & $1.701^{\bullet \bullet \bullet}$ & \\
\hline & & & [.373] & \\
\hline \multirow{2}{*}{$\begin{array}{l}\text { Hiring newcomers without mental disorder diagnoses } \times \text { Hiring newcomers leaving } \\
\text { unhealthy organizations }\end{array}$} & & & $4.616^{\bullet \bullet \bullet}$ & \\
\hline & & & [.428] & \\
\hline \multirow[t]{2}{*}{ Managerial position } & $1.167^{\bullet \bullet \bullet}$ & $1.166^{\bullet \bullet \bullet}$ & $1.163^{\bullet \bullet \bullet}$ & $.772^{\bullet \bullet \bullet}$ \\
\hline & {$[.012]$} & {$[.016]$} & [.012] & {$[.016]$} \\
\hline \multirow[t]{2}{*}{ Managerial position $\times$ Hiring newcomers with mental disorder diagnoses } & & & & $1.133^{\bullet \bullet \bullet}$ \\
\hline & & & & [.077] \\
\hline \multirow[t]{2}{*}{ Managerial position $\times$ Hiring newcomers without mental disorder diagnoses } & & & & $.863^{\bullet \bullet \bullet}$ \\
\hline & & & & [.104] \\
\hline \multirow[t]{2}{*}{ Managerial position $\times$ Hiring newcomers leaving unhealthy organizations } & & & & $1.232^{\bullet \bullet}$ \\
\hline & & & & {$[.056]$} \\
\hline \multirow[t]{2}{*}{ Tenure } & .038 & .082 & .043 & .016 \\
\hline & {$[.044]$} & {$[.076]$} & [.083] & {$[.021]$} \\
\hline \multirow[t]{2}{*}{ Prior mental disorder incident } & $.071^{\cdots}$ & $.070^{\bullet \bullet \bullet}$ & $.071^{\bullet \bullet}$ & $.070 \cdots$ \\
\hline & {$[.000]$} & {$[.000]$} & {$[.000]$} & {$[.000]$} \\
\hline \multirow[t]{2}{*}{ Medical history } & $.663^{\bullet \bullet}$ & $.715^{\bullet \bullet}$ & $.726^{\bullet \bullet \bullet}$ & $.766^{\bullet \bullet \bullet}$ \\
\hline & {$[.015]$} & {$[.017]$} & {$[.019]$} & {$[.021]$} \\
\hline \multirow[t]{2}{*}{ Education } & $.103^{\bullet \bullet \bullet}$ & $.094^{\bullet \bullet \bullet}$ & $.104^{\bullet \bullet \bullet}$ & $.095^{\bullet \bullet \bullet}$ \\
\hline & {$[.003]$} & {$[.004]$} & {$[.003]$} & {$[.004]$} \\
\hline \multirow[t]{2}{*}{ Age } & $.015^{\bullet \bullet \bullet}$ & $.014^{\bullet \bullet \bullet}$ & $.016^{\bullet \bullet \bullet}$ & $.014^{\bullet \bullet \bullet}$ \\
\hline & {$[.001]$} & {$[.001]$} & {$[.001]$} & {$[.001]$} \\
\hline \multirow[t]{2}{*}{ Gender } & .000 & .000 & .000 & .000 \\
\hline & {$[.000]$} & {$[.000]$} & [.003] & {$[.002]$} \\
\hline \multirow[t]{2}{*}{ Personal income } & $.026 \bullet \bullet$ & $.029^{\bullet \bullet \bullet}$ & $.026^{\bullet \bullet \bullet}$ & $.027^{\bullet \bullet \bullet}$ \\
\hline & {$[.008]$} & {$[.007]$} & {$[.008]$} & {$[.008]$} \\
\hline \multirow[t]{2}{*}{ Occupation } & .023 & -.046 & -.218 & -.116 \\
\hline & [.154] & [.158] & [.177] & {$[.166]$} \\
\hline \multirow[t]{2}{*}{ Mental disorder prevalence in the hiring organization } & $.047^{\bullet \bullet}$ & $.044^{\bullet \bullet \bullet}$ & $.042^{\bullet \bullet \bullet ~}$ & $.043^{\bullet \bullet}$ \\
\hline & {$[.001]$} & {$[.001]$} & {$[.001]$} & {$[.001]$} \\
\hline \multirow[t]{2}{*}{ Firm size } & $-.001^{\bullet \bullet \bullet}$ & $.000^{\bullet \bullet \bullet}$ & $-.001^{\bullet \bullet \bullet}$ & $-.001^{\bullet}$ \\
\hline & {$[.000]$} & {$[.000]$} & {$[.000]$} & {$[.000]$} \\
\hline \multirow[t]{2}{*}{ Year of job change } & -.02 & -.001 & -.021 & .006 \\
\hline & {$[.022]$} & [.017] & [.025] & [.019] \\
\hline Industry dummies & Included & Included & Included & Included \\
\hline \multirow[t]{2}{*}{ Constant } & $1.437^{\bullet \bullet \bullet}$ & $.090^{\bullet \bullet}$ & $1.467^{\bullet \bullet}$ & $.066^{\bullet \bullet \bullet}$ \\
\hline & {$[.013]$} & {$[.016]$} & {$[.017]$} & {$[.020]$} \\
\hline Number of observations & 144,117 & 144,117 & 144,117 & 144,117 \\
\hline R-squared & .276 & .297 & .306 & .304 \\
\hline F test & $32.279^{\bullet \bullet \bullet}$ & $33.232^{\bullet \bullet \bullet}$ & $32.325^{\bullet \bullet \bullet}$ & $36.316^{\bullet \bullet \bullet}$ \\
\hline$\Delta \mathrm{R}$-squared & - & .0057 & .0296 & .0272 \\
\hline$\Delta \mathrm{F}$ test & - & $32.18^{\bullet \bullet \bullet}$ & $52.50^{\bullet \bullet \bullet}$ & $68.07^{\bullet \bullet}$ \\
\hline
\end{tabular}

$\bullet p<.05 ; \cdots p<.01 ; \cdots p<.001$.

organization's incidence rate. We also find that hiring newcomers without mental disorder diagnoses but whose previous organization was unhealthy has a positive and significant effect $\left(\beta_{i}=1.401 ; p<.001\right)$ (hiring newcomers without mental disorder diagnoses $\times$ hiring newcomers leaving unhealthy organizations). This effect accounts for 2.47 percent $\left(\omega^{2}=0.0247 ; \mathrm{Cl}[0.0095\right.$; 0.0269]) variability in incidence rates.

When examining the three mental disorders separately (model 3 in Tables 3, 4 , and 5), we find a positive significant effect for hiring individuals leaving unhealthy organizations when diagnosed with depression $\left(\beta_{i}=0.132\right.$; 
Table 5. Hypotheses Tests: OLS with Robust Standard Errors. Dependent Variable: Stress-Related Disorders Incidence Rate in $t+3$

\begin{tabular}{|c|c|c|c|c|}
\hline & Model 1 & Model 2 & Model 3 & Model 4 \\
\hline \multirow[t]{2}{*}{ Hiring newcomers with mental disorder diagnoses } & & $1.243^{\bullet \bullet \bullet}$ & $1.382^{\bullet \bullet \bullet}$ & $1.427^{\bullet \bullet \bullet}$ \\
\hline & & [.443] & {$[.503]$} & {$[.549]$} \\
\hline \multirow[t]{2}{*}{ Hiring newcomers without mental disorder diagnoses } & & -.043 & -.010 & -.077 \\
\hline & & {$[.078]$} & [.018] & [.109] \\
\hline \multirow[t]{2}{*}{ Hiring newcomers leaving unhealthy organizations } & & $2.026^{\bullet \bullet}$ & $2.353^{\bullet \bullet \bullet}$ & $1.886^{\bullet \bullet \bullet}$ \\
\hline & & {$[.617]$} & [.684] & {$[.514]$} \\
\hline \multirow{2}{*}{$\begin{array}{l}\text { Hiring newcomers with mental disorder diagnoses } \times \text { Hiring newcomers leaving } \\
\text { unhealthy organizations }\end{array}$} & & & $3.674^{\bullet \bullet}$ & \\
\hline & & & {$[.704]$} & \\
\hline \multirow{2}{*}{$\begin{array}{l}\text { Hiring newcomers without mental disorder diagnoses } \times \text { Hiring newcomers leaving } \\
\text { unhealthy organizations }\end{array}$} & & & $2.012^{\bullet}$ & \\
\hline & & & [1.179] & \\
\hline \multirow[t]{2}{*}{ Managerial position } & $2.569^{\bullet \bullet \bullet}$ & $2.712^{\bullet \bullet \bullet}$ & $1.974^{\bullet \bullet \bullet}$ & $1.137^{\bullet}$ \\
\hline & [.202] & {$[.151]$} & {$[.266]$} & [.354] \\
\hline \multirow[t]{2}{*}{ Managerial position $\times$ Hiring newcomers with mental disorder diagnoses } & & & & $2.194^{\bullet \bullet \bullet}$ \\
\hline & & & & {$[.215]$} \\
\hline \multirow[t]{2}{*}{ Managerial position $\times$ Hiring newcomers without mental disorder diagnoses } & & & & $1.701^{\bullet \bullet}$ \\
\hline & & & & [.173] \\
\hline \multirow[t]{2}{*}{ Managerial position $\times$ Hiring newcomers leaving unhealthy organizations } & & & & $1.934^{\bullet \bullet}$ \\
\hline & & & & {$[.210]$} \\
\hline \multirow[t]{2}{*}{ Tenure } & .053 & .020 & .023 & .046 \\
\hline & [.081] & {$[.025]$} & {$[.057]$} & {$[.040]$} \\
\hline \multirow[t]{2}{*}{ Prior mental disorder incident } & $.022^{\bullet}$ & $.020^{\bullet}$ & $.020^{\bullet}$ & $.022^{\bullet \bullet}$ \\
\hline & {$[.011]$} & {$[.011]$} & {$[.011]$} & {$[.011]$} \\
\hline \multirow[t]{2}{*}{ Medical history } & $3.052^{\bullet \bullet \bullet}$ & $3.126^{\bullet \bullet \bullet}$ & $2.037^{\bullet \bullet \bullet}$ & $3.214^{\bullet \bullet \bullet}$ \\
\hline & {$[.450]$} & {$[.462]$} & {$[.566]$} & {$[.472]$} \\
\hline \multirow[t]{2}{*}{ Education } & .669 & .674 & .634 & .623 \\
\hline & {$[.554]$} & {$[.546]$} & {$[.521]$} & {$[.602]$} \\
\hline \multirow[t]{2}{*}{ Age } & $.026^{\bullet \bullet \bullet}$ & $.029 \bullet \bullet$ & $.026^{\bullet \bullet \bullet}$ & $.027^{\bullet \bullet \bullet}$ \\
\hline & {$[.008]$} & {$[.007]$} & {$[.008]$} & {$[.008]$} \\
\hline \multirow[t]{2}{*}{ Gender } & .000 & .000 & .000 & .000 \\
\hline & {$[.000]$} & {$[.000]$} & [.001] & {$[.000]$} \\
\hline \multirow[t]{2}{*}{ Personal income } & $-.001^{\bullet \bullet}$ & $-.004^{\bullet \bullet \bullet}$ & $-.001^{\bullet \cdots}$ & $-.001^{\bullet}$ \\
\hline & [.001] & {$[.000]$} & {$[.000]$} & {$[.000]$} \\
\hline \multirow[t]{2}{*}{ Occupation } & .067 & $.007^{\bullet \bullet \bullet}$ & $.007^{\bullet \bullet \bullet}$ & $.071^{\bullet \bullet}$ \\
\hline & [.003] & {$[.000]$} & {$[.000]$} & {$[.000]$} \\
\hline \multirow[t]{2}{*}{ Mental disorder prevalence in the hiring organization } & $.047^{\bullet \bullet}$ & $.044^{\cdots \bullet}$ & $.042^{\bullet \bullet}$ & $.043^{\bullet \bullet}$ \\
\hline & {$[.001]$} & {$[.001]$} & {$[.001]$} & {$[.001]$} \\
\hline \multirow[t]{2}{*}{ Firm size } & .023 & -.046 & -.218 & -.116 \\
\hline & {$[.154]$} & [.158] & {$[.177]$} & {$[.166]$} \\
\hline \multirow[t]{2}{*}{ Year of job change } & -.193 & -.198 & -.246 & -.236 \\
\hline & [.201] & [.202] & {$[.214]$} & {$[.206]$} \\
\hline Industry dummies & Included & Included & Included & Included \\
\hline \multirow[t]{2}{*}{ Constant } & $-1.840^{\bullet \bullet}$ & $-1.655^{\bullet \bullet \bullet}$ & $-1.381^{\cdots \bullet}$ & $-1.172 \bullet \bullet$ \\
\hline & [.191] & {$[.216]$} & {$[.226]$} & [.193] \\
\hline Number of observations & 144,117 & 144,117 & 144,117 & 144,117 \\
\hline R-squared & .255 & .251 & .267 & .260 \\
\hline$F$ test & $22.3217^{\cdots \bullet \bullet}$ & $25.29404^{\bullet \bullet \bullet}$ & $23.31604^{\bullet \bullet \bullet}$ & $25.85678^{\bullet \bullet \bullet}$ \\
\hline$\Delta \mathrm{R}$-squared & - & .0851 & .0057 & .0296 \\
\hline$\Delta \mathrm{F}$ test & - & $20.23^{\bullet \bullet \bullet}$ & $32.18^{\bullet \bullet \bullet}$ & $52.50^{\bullet \bullet \bullet}$ \\
\hline
\end{tabular}

$\bullet p<.05 ; \cdot \bullet p<.01 ; \cdots p<.001$.

$\left.p<.001, \omega^{2}=0.0229 ; \mathrm{Cl}[0.0156 ; 0.0282]\right)$, anxiety $\left(\beta_{\mathrm{i}}=1.126 ; p<.001\right.$, $\left.\omega^{2}=0.0853 ; \mathrm{Cl}[0.0787 ; 0.0881]\right)$, and stress-related disorders $\left(\beta_{i}=2.353\right.$; $\left.p<.001, \omega^{2}=0.1343 ; \mathrm{Cl}[0.1125 ; 0.1391]\right)$. This is again the case for both diagnosed and undiagnosed newcomers leaving unhealthy organizations (hiring newcomers leaving unhealthy organizations $\times$ hiring newcomers with mental disorder diagnoses or hiring newcomers without mental disorder diagnoses), further supporting $\mathrm{H} 2$ for all three distinct mental disorders. Notably, when examining the individuals leaving unhealthy organizations (interactions in 


\section{Figure 3. Interaction Effects between Hiring Newcomers with Mental Disorder Diagnoses and Hiring Newcomers Leaving Unhealthy Organizations}

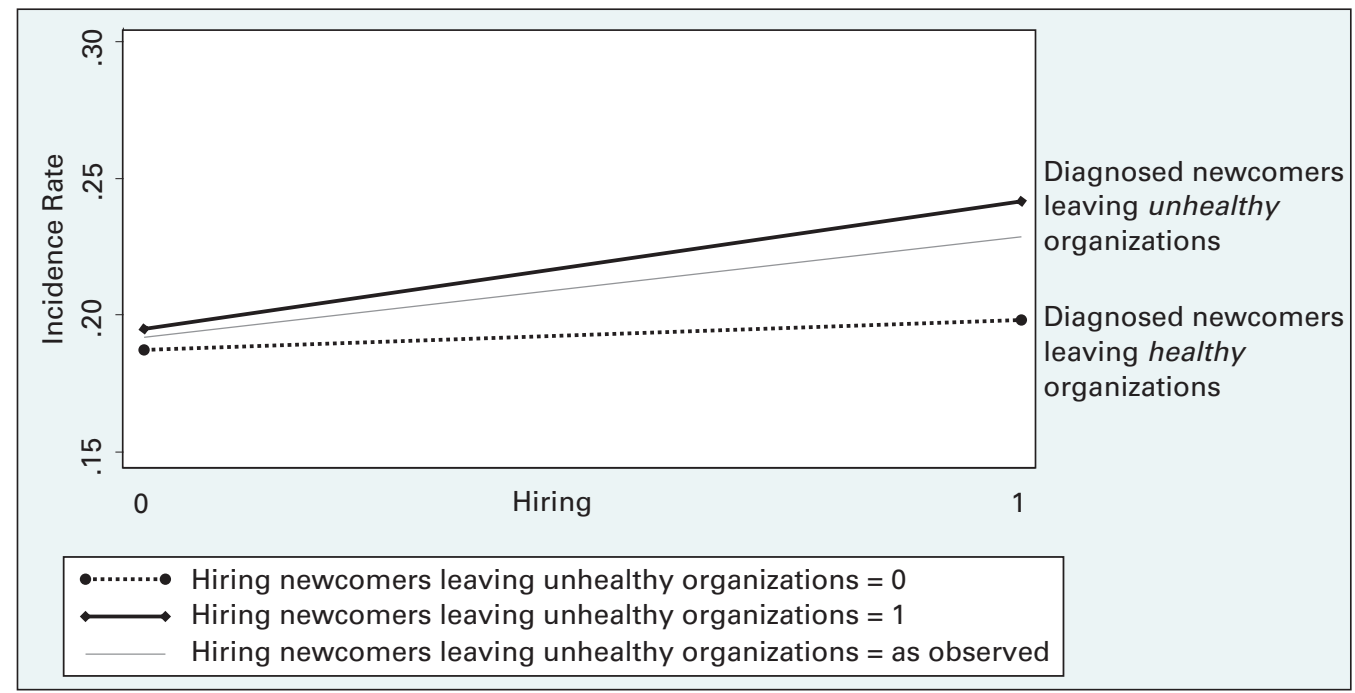

model 3; Tables 3, 4, and 5), differences are apparent between depression, anxiety, and stress-related diagnoses. The incidence rates for depression and anxiety experience a stronger effect when considering hiring newcomers without mental disorder diagnoses compared with hiring newcomers with mental disorder diagnoses. The reverse is the case when considering stress-related disorders: hiring newcomers with mental disorder diagnoses has a stronger effect than hiring newcomers without mental disorder diagnoses.

The interaction effects found in Table 2 are plotted in Figures 3 and 4. Figure 3 shows a remarkably stronger effect on the incidence rate when hiring diagnosed newcomers leaving unhealthy organizations as compared with hiring diagnosed newcomers leaving healthy organizations. Figure 4 shows a clear positive effect on the incidence rate when hiring undiagnosed newcomers from unhealthy (compared with healthy) organizations.

$\mathrm{H} 3$ predicts that the contagion effect of mental disorders will be stronger if the hired newcomer takes up a managerial post in the hiring firm. Model 5 is constructed similar to model 4 except that instead of testing all hired newcomers, the effect is tested for newcomers hired to fill managerial positions. Model 6 tests all interactions together, showing similar effects. We find that managerial position has a significant moderating effect on both main effects that we stated in $\mathrm{H} 1$ and $\mathrm{H} 2$.

First, the interaction effect of managerial position $\times$ hiring newcomers with mental disorder diagnoses was significant $\left(\beta_{i}=2.572 ; p<.001\right)$, indicating that the incidence rate in the hiring organization increased more strongly when hiring a diagnosed manager than when hiring a diagnosed employee (nonmanager). The effect size further supports this $\left(\omega^{2}=0.0868 ; \mathrm{Cl}[0.0726\right.$; 0.0920]). Figure 5 illustrates this interaction effect, showing that the effects of hiring a diagnosed newcomer are especially pronounced when the newcomer holds a managerial role. Examining model 4 in Tables 3, 4 and 5, we find similar 


\section{Figure 4. Interaction Effects between Hiring Newcomers without Mental Disorder Diagnoses and Hiring Newcomers Leaving Unhealthy Organizations}

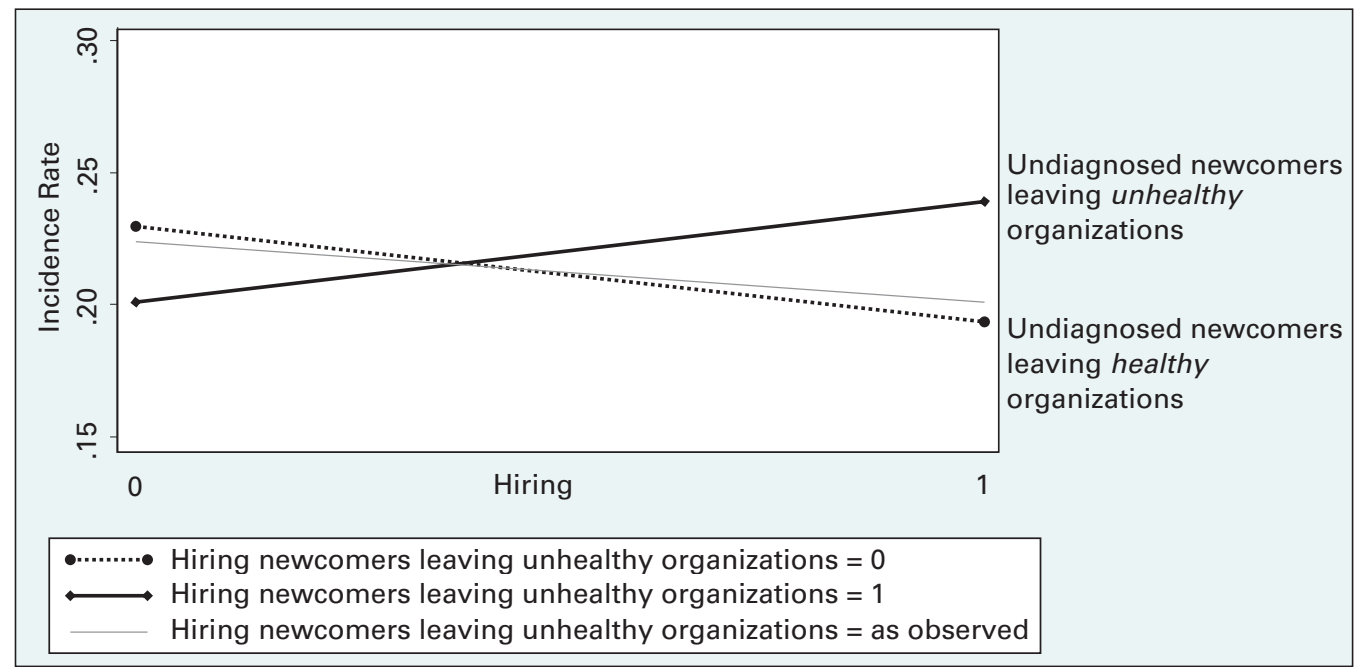

positive, significant effects for each mental disorder diagnosis. The interaction effect of managerial position $\times$ hiring newcomers with mental disorder diagnoses was significant when considering individuals diagnosed with depression $\left(\beta_{\mathrm{i}}=0.824 ; p<.001, \omega^{2}=0.0189 ; \mathrm{Cl}[0.0107 ; 0.0255]\right)$, anxiety $\left(\beta_{\mathrm{i}}=1.133 ;\right.$ $\left.p<.001, \omega^{2}=0.0145 ; \mathrm{Cl}[0.067 ; 0.0220]\right)$, and stress-related disorders $\left(\beta_{\mathrm{i}}=\right.$ $\left.2.194 ; p<.001, \omega^{2}=0.194 ; \mathrm{Cl}[0.0126 ; 0.0221]\right)$.

Second, the interaction effect of managerial position $\times$ hiring newcomers leaving unhealthy organizations was significant $\left(\beta_{\mathrm{i}}=1.109 ; p<.001\right)$, indicating that the incidence rate in the hiring organization increased more strongly when hiring a manager leaving an unhealthy organization compared with an employee (non-manager) leaving an unhealthy organization. Figure 6 further supports that the effects of hiring from an unhealthy organization are especially pronounced when the newcomer holds a managerial role. The effect sizes for undiagnosed managers $\left(\omega^{2}=0.0313, \mathrm{Cl}\right.$ [0.0118; 0.0339] show a stronger effect than the previous effect sizes calculated for non-managerial newcomers. Considering the effects of each mental disorder diagnosis, we find similar positive effects for managers when considering the incidence rates for depression $\left(\beta_{\mathrm{i}}=0.766 ; p<.001, \omega^{2}=0.0711 ; \mathrm{Cl}[0.0107 ; 0.0255]\right)$, anxiety $\left(\beta_{\mathrm{i}}=1.232\right.$; $\left.p<.001, \omega^{2}=0.0643 ; \mathrm{Cl}[0.0596 ; 0.0728]\right)$, and stress-related disorders $\left(\beta_{i}=\right.$ $\left.1.934 ; p<.001, \omega^{2}=0.1037 ; \mathrm{Cl}[0.0849 ; 0.1109]\right)$. Altogether, we find support for H3.

\section{Robustness Tests}

First, we tested our key assumption that newcomers' mental disorders would persist after the job change. It might be that newcomers recover after entering a new work environment. We considered continuing medical treatment after the job change as an indicator of mental disorder persistence and exiting treatment after the job change as an indicator of recovery. Using a logistic 
Figure 5. Interaction Effects between Hiring Newcomers with Mental Disorder Diagnoses and Managerial Position

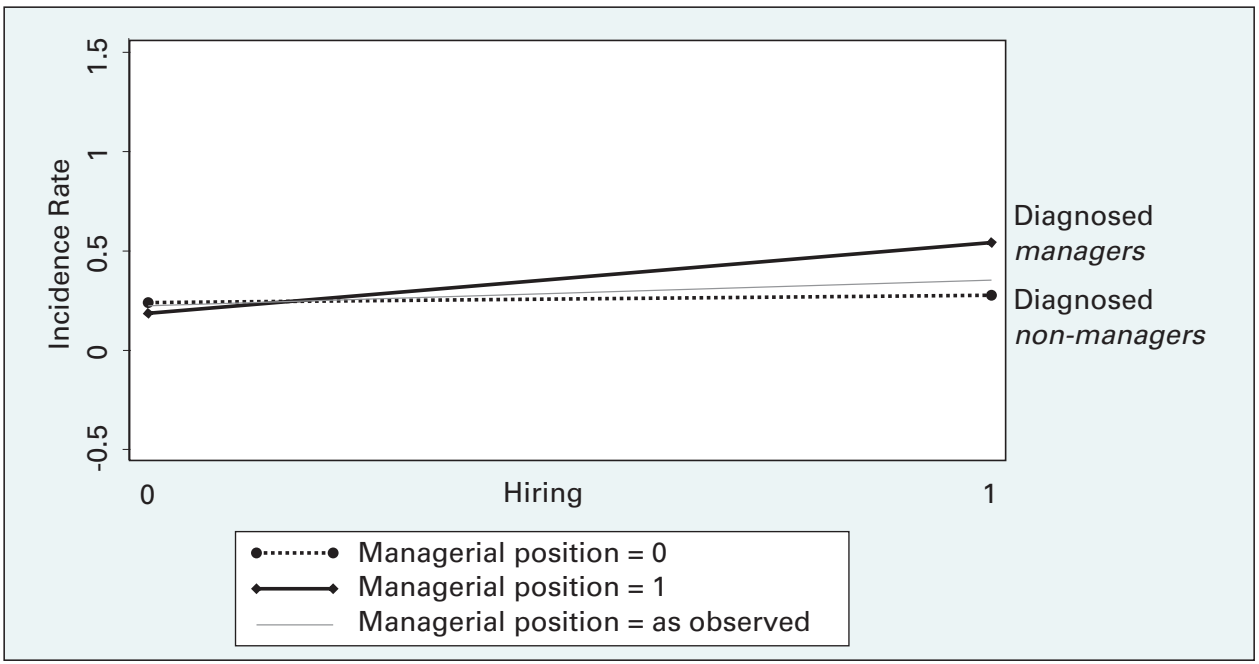

Figure 6. Interaction Effects between Hiring Newcomers from Unhealthy Organizations and Managerial Position

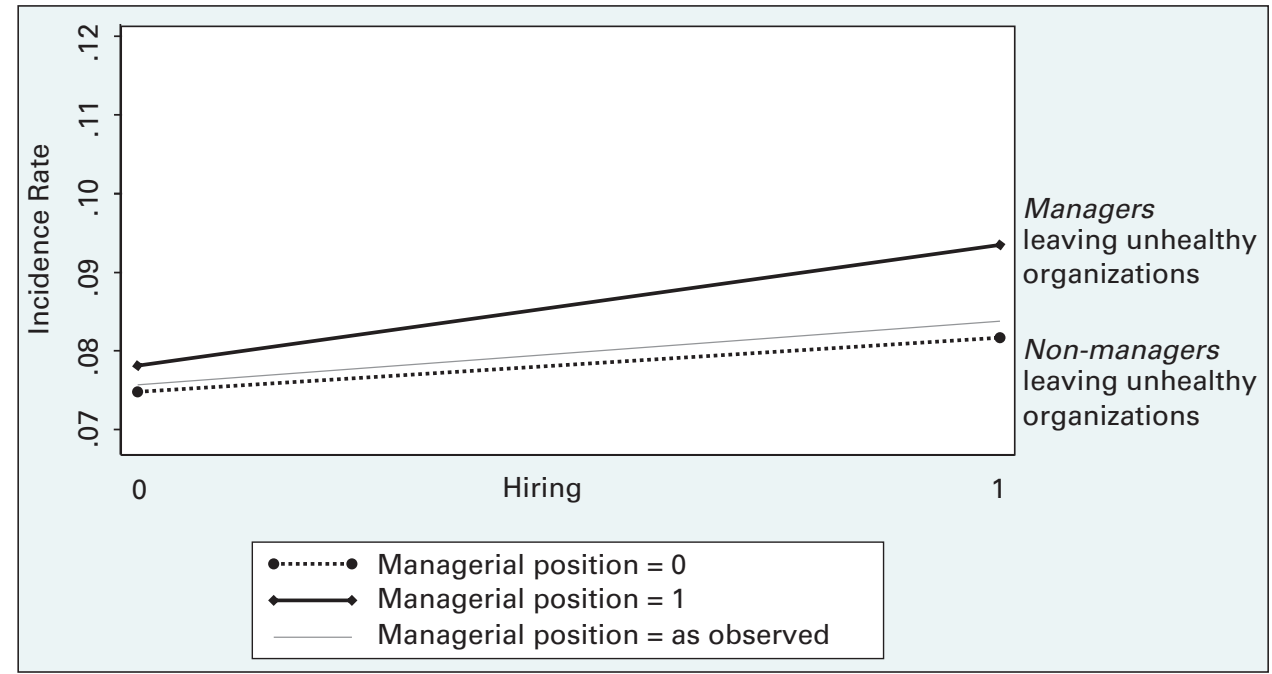

regression model, we examined the likelihood of a diagnosed individual exiting treatment as the outcome and job change as a predictor (along with the control variables used in our main model). Job change had no significant effect on the likelihood of a diagnosed individual exiting treatment. This provides support for our idea that a job change does not produce an immediate recovery, but that mental disorder symptoms persist. 
Second, we conducted two robustness tests relating to our assumptions about newcomers leaving unhealthy organizations. To examine our idea that undiagnosed newcomers leaving unhealthy organizations may have subclinical or subthreshold mental disorder symptoms that have not (yet) become apparent in a formal mental disorder diagnosis, we examined what happened to these undiagnosed newcomers after their job change. A logistic regression analysis with undiagnosed individuals showed that leaving an unhealthy organization was significantly and positively related to receiving a depression, anxiety, or stress-related disorder diagnosis within the first year of their employment in their new jobs $\left(\beta_{i}=2.752 ; p<.001\right)$. This supports our argument that undiagnosed newcomers from unhealthy organizations may "carry" a mental disorder without being diagnosed yet. We also examined the imprinting idea that having spent longer times in unhealthy organizations will increase the likelihood that employees adopted the negative emotions, cognitions, and behaviors observed in that unhealthy environment. We found a significant interaction between leaving unhealthy organizations and the tenure of job changers in these unhealthy organizations on the incidence of mental disorders in a hiring organization $\left(\beta_{\mathrm{i}}=\right.$ 0.028; $p<.001$, see model 5 in Table 2). Thus, hiring newcomers who have spent longer (compared with shorter) times in unhealthy organizations more strongly increases the incidence rates of mental disorders in hiring organizations. These findings support our theoretical notions that unhealthy organizations can have a long-lasting negative impact not only for the individuals leaving these organizations but also for other organizations hiring from these unhealthy organizations.

Third, we varied the dependent variable. Instead of using incidence rate, we used the absolute number of mental disorders in the hiring organization in the three years following the hire, employing a zero-inflated Poisson model. A LaGrange multiplier test (Greene, 2011) confirmed that our data do not suffer from over-dispersion and suggested the need to run the zero-inflated version of the Poisson estimation based on the Akaike and Bayesian information criteria. Our findings remain robust with this alternative model specification.

Finally, we tested all our models using time lags of one, two, four, and five years to cover a broader range than the three-year lag applied in our main model. Overall (with the exception of the time lag of one year), our robustness checks confirm our hypotheses with only minor differences in the strengths of the significance or magnitude of the coefficients. Allowing only a single year for symptoms, diagnosis, and registration of mental disorders makes it difficult to capture all cases either because our data capture job changes only from one year to another or because the time from initial exposure to a mental disorder to actual diagnosis can take more than one year. ${ }^{\mathbf{8}}$

\section{DISCUSSION}

Our study aimed to establish a new way of seeing mental disorders in business: as phenomena that spread cross-organizationally and thus are more pervasive, enduring, and complex than previously thought. By looking at mental disorders through an infectious disease epidemiology lens, we help explain transmission within and across organizations. Most important, our findings

\footnotetext{
${ }^{\mathbf{8}}$ Results from robustness tests are all available on request from the authors.
} 
show that employee mobility is a major driver of transmission and contagion of mental disorders across organizational boundaries. For a hiring organization, the number of mental disorder diagnoses in their existing workforce increases after hiring newcomers with mental disorders or newcomers leaving unhealthy organizations irrespective of whether individuals have been formally diagnosed with a mental disorder. ${ }^{\mathbf{9}}$ The effects are particularly strong for newcomers hired into managerial positions and newcomers with long previous tenures in unhealthy organizations. By showing these negative consequences of mental disorder contagion across organizational boundaries, our study has important implications for both theory and management practice.

\section{Theoretical Implications}

This study provides several important theoretical insights for scholars dealing with employee mobility and mental disorders in the workplace both from an organizational perspective (e.g., in the fields of strategic management and strategic human resources management) and from an individual perspective (e.g., in the fields of organizational behavior, organizational psychology, and occupational health research).

Organization-level focus. For scholars with an organization-level focus, understanding the consequences of employee mobility is extremely relevant in light of the ongoing trend for individuals to switch employers frequently rather than spending an entire career in a single organization (Raffiee and Byun, 2020). This makes each organization simultaneously a take-off place for leaving employees and a landing place for employees coming from outside workforces (Bidwell, 2011). Our finding that employee mobility can be a key driver of severe mental disorder contagion contradicts most of the existing studies on employee mobility, which suggest that organizations benefit from external hiring (Corredoira and Rosenkopf, 2010; Cappelli and Keller, 2014; Mawdsley and Somaya, 2016). Building on the idea that "mobility of personnel among organizations provides a way of spreading information" (Arrow, 1962: 615), new hires are mostly thought of as valuable sources of important knowledge (Rosenkopf and Almeida, 2003; Song, Almeida, and Wu, 2003), ideas, or innovations (Rao and Drazin, 2002; Singh and Agrawal, 2011). Therefore, both scholars and practitioners often expect external hiring to increase firm performance (Fahrenkopf, Guo, and Argote, 2020). But a few studies have started questioning this overly positive view of employee mobility. The portability of

\footnotetext{
$\mathbf{9}$ Interestingly, we found disorder-specific differences for undiagnosed newcomers leaving unhealthy organizations. For stress-related disorders, hiring undiagnosed newcomers was less contagious than hiring diagnosed newcomers. For depression and anxiety, hiring undiagnosed newcomers was more contagious than hiring diagnosed newcomers. We suspect that these differential effects might be due to different numbers of "hidden" full-blown mental disorders among these undiagnosed individuals, caused by stigma. Depression and anxiety might be more stigmatized than stress-related disorders (because people tend to ascribe depression and anxiety more to within-person causes such as a "weak personality"; Yokoya et al., 2018), thereby preventing individuals with full-blown depression and anxiety symptoms from seeking treatment and being diagnosed (Bianchi et al., 2016). Therefore, contagion effects might be stronger, as the undiagnosed depressed and anxious newcomers might include proportionally more individuals with highly contagious but "hidden" full-blown symptoms.
} 
performance paradox indicates that, after entering a new organization, some newcomers do not live up to their potential, fail to replicate prior good performance, or even experience a performance decline (Groysberg, Lee, and Nanda, 2008; Bidwell, 2011; Raffiee and Byun, 2020). Dokko, Wilk, and Rothbard (2009: 51) also shined a more critical light on employee mobility by asking, "What do organizations get when they hire experienced workers?" The authors argued that prior experience from previous employment includes not only valuable skills and knowledge but also "cognitive and behavioral rigidities in the form of schemas and scripts that can impede performance in the new firm" (Dokko, Wilk, and Rothbard, 2009: 52). Our study supports this view and shows that, in addition to positive resources, new employees may transfer characteristics that are harmful to the hiring organization. ${ }^{\mathbf{1 0}}$

Moreover, this study offers a new cross-organizational understanding of mental disorders in business, which should also be important for scholars interested in organization-level phenomena. Our use of an infectious disease epidemiology metaphor reinforces the anecdotal notion (e.g., Cooper and Cartwright, 1994) that some organizations are unhealthier-and thus more "infectious" than others, indicated by the different prevalence rates of mental disorders in the respective workforces. Extending prior findings, we show that these unhealthy organizations do not only have an immediate harmful impact on the health and well-being of their own workforce. Instead, our findings suggest that employee mobility and contagion effects also result in unhealthy organizations having the potential to reduce the health of other organizations. Our wider, epidemiological focus thus reveals the invisible power of outside organizations to affect the health and well-being of internal workforces.

Individual-level focus. For scholars with an individual-level focus, our findings advance knowledge about the genesis of mental disorders in the workplace. In showing that mental disorders can cross organizational borders, we extend prior approaches that have identified the important role of adverse job demands and working conditions as antecedents of mental disorders. We also build upon and carry forward prior research showing the important impact of social contagion processes within dyads, groups, and organizations (e.g., Ashkanasy and Humphrey, 2011; Ashkanasy and Dorris, 2017). Our finding that newcomers entering an organization from the outside can initiate contagion effects of mental disorders in the new workplace adds a new explanation for the question of why employees in a (hiring) organization may develop mental disorders. Importantly, our findings indicate that symptoms of mental disorders can persist after a job change, contradicting previous suggestions that leaving an unhealthy work environment may facilitate recovery (e.g., Wright and Bonett, 1992; Liljegren and Ekberg, 2009; Equeter, Jepsen, and Hellemans,

\footnotetext{
${ }^{10}$ Following a thought-provoking reviewer comment, we would like to acknowledge that light symptoms and non-clinical manifestations of some mental disorders can also have an adaptive side, which might be beneficial for organizations. For instance, Ein-Dor and colleagues (Ein-Dor et al., 2010; Ein-Dor and Tal, 2012; Ein-Dor and Perry, 2014) demonstrated that an anxious individual can benefit a social group by alerting the others to threat, danger, or deceit. This might be especially beneficial in professional settings where high vigilance is important (e.g., national security). Shedding more light on the role of mental disorders in different industries would thus be a relevant future research endeavor.
} 
2018). Shifting the view from an intra-individual and intra-organizational etiology to a cross-organizational distribution of mental disorders thus reveals an additional impactful way of understanding how mental disorders emerge even in previously healthy employees, teams, and organizations.

Considering the dynamics of employee mobility in modern labor markets should also be relevant for scholars with an individual-level focus. We add to previous research that has pointed out that prior experience in another organization can become an influential career imprint (Beyer and Hannah, 2002; Higgins, 2006; Tilcsik, 2014) but that rarely considered the negative effects such imprinting could have for individuals entering new jobs (Kidwell, Eddleston, and Kellermanns, 2018). Our study provides additional knowledge about what employees transfer between organizations when they change jobs. By showing that symptoms of mental disorders can be transferred across organizational boundaries, we highlight that the positive employee characteristics typically considered when examining employee mobility, such as knowledge, capabilities, and network ties (Mawdsley and Somaya, 2016), are only part of the overall package that newly hired employees carry with them. Given the detrimental individual-level and firm-level consequences of mental disorders, their spread in organizations can be a deleterious side effect of employee mobility, which reduces the benefits of gaining human capital. We encourage future research to explore additional toxic imprints that employees might keep after having left an organization, such as elements of an unhealthy corporate culture (Kim and Toh, 2019).

\section{Practical Implications}

Hiring human resources from external labor markets can be an important and valuable source of competitive advantage (Cappelli and Keller, 2014). This study aims to create awareness of negative side effects of external hiring. Our findings show that organizations may unintentionally "implant" mental disorders into their existing workforce through external hiring, leading to noxious contagion effects among existing employees. Given these simultaneous benefits and possible negative side effects of external hiring, practical implications of this study are neither straightforward nor ready-to-apply. Importantly, we clearly pronounce against taking oversimplifying measures such as blindly rejecting candidates (presumably) diagnosed with mental disorders or candidates coming from (presumably) unhealthy organizations. Using mental disorder diagnoses as recruitment criteria is not only unethical but also unhelpful given that individuals with and without mental disorder diagnoses can initiate these contagion effects. Instead, we agree with Guest (2017) that firms have an ethical obligation not to duck away but to actively care for employees' well-being, given that the increasing incidence of mental disorders is a societal reality that can partially be attributed to working conditions in modern organizations. We suggest that the consequences of mental disorders in firms should decisively depend on organizations' overall approach and commitment to managing employees' mental health (Peccei and Van De Voorde, 2019; Ho and Kuvaas 2020).

One key to preventing negative contagion effects should be the management of the new human resources after the hiring process. Organizations should develop appropriate strategies to prevent the potential spread of mental 
disorders in the organization and to contribute positively to the well-being of the overall workforce. To support newly hired employees, it will be important that these newcomers' potentially existing or subliminal mental disorder symptoms do not become aggravated after the job transition. A "laissez-faire style" toward employee socialization that firms commonly apply is therefore risky (Liu et al., 2015). Instead, organizations should grasp the opportunity to shape newcomers' initial work experience actively through organizationinitiated onboarding procedures (Bauer et al., 2007; Saks and Gruman, 2011). This is particularly critical since newly hired employees often experience uncertainty, anxiety, and stress (Ellis et al., 2015), which might reinforce prior existing symptoms. Appropriately designed organizational socialization processes may equip newly hired employees with important relational and structural resources to help them deal effectively with the new situation (Fang, Duffy, and Shaw, 2011). To support both newly hired employees and the existing workforce, an organizational environment that identifies, amplifies, and concentrates on individuals' strengths may serve as an effective prevention against the development and contagion of mental disorders (Seligman, 2002). Organizations should thus cultivate a climate of inclusion (Shore et al., 2011) wherein employees support each other and accept individual diversity. A supportive organizational culture in which individuals are not afraid of discrimination or harassment should also encourage employees to seek help if symptoms of mental disorders develop or flare up, thus counteracting the social stigma of mental disorders (Feldman and Crandall, 2007; Owen, Thomas, and Rodolfa, 2013).

\section{Limitations and Directions for Future Research}

As with any study, there are limitations that need to be acknowledged. First, the comprehensive, objective, and longitudinal data we used provide a strong foundation for testing our assumptions. Rather than using self-reported questionnaires to measure mental disorders, we assessed mental disorders with professional diagnoses based on the ICD-10 criteria. However, data from national registries have been criticized for overlooking mental disorders occurring outside of psychiatric medical settings (Schaefer et al., 2017). Our broad approach of combining diagnoses from hospitals, general practitioners, and specialist doctors increases the chances of capturing mental health diagnoses made outside a psychiatric setting. Nevertheless, by complementing the ICD10 criteria with more in-depth measures, such as diagnostic questionnaires or clinical observations, future research could reveal contagion effects that do not ultimately result in clinical diagnoses. Such measures could also shine a spotlight on the exact mental state of undiagnosed newcomers and disentangle the effects of those having full-blown versus subclinical symptoms. Future research may also expand the contagion idea to broader and more diverse symptoms and disorders. For example, in addition to depression, anxiety, and stress, it could be interesting to examine how symptoms of personality disorders (e.g., narcissism; Judge, LePine, and Rich, 2006; Chatterjee and Hambrick, 2007), eating disorders (Crandall, 1988), or addictive behaviors (Rosenquist et al., 2010) spread within and across organizations.

Second, our choice of an epidemiological (rather than an etiological) approach does not intend or allow observation of in-depth individual-level 
processes surrounding mental disorder contagion. Future research could complement our findings by applying more individual-centered research methodologies to study both newcomers (i.e., carriers of mental disorders) and employees in the hiring organization (i.e., the susceptible individuals). Potentially "infective" newcomers could be observed during the early critical phases after entering the new organization to examine when and under what conditions their mental disorder-related symptoms persist, decline (recovery), or flare up (exacerbation). For susceptible employees in the hiring organization, future research should examine whether individuals differ in their likelihood of being "infected" by mental disorder contagion in the workplace. Medical science claims that individuals can differ in their susceptibility to infectious diseases or can even be immune (cf. Bonita, Beaglehole, and Kjellström, 2006). Similarly, individuals may differ in their vulnerability or resilience to developing mental disorders (Staw and Ross, 1985; Southwick, Vythilingam, and Charney, 2005; Haeffel and Hames, 2014) and in their likelihood to "tune in" to expressions of mental disorder displayed by other individuals (llies, Wagner, and Morgeson, 2007; Sy and Choi, 2013). Thus, although susceptible employees in a hiring organization are exposed equally to an "infective" newcomer, the contagion effects might not affect all of them equally. Likewise, future research could explore whether organizations—on a firm level—differ in their susceptibility or resilience to mental disorder contagion. For instance, chains of contagion might get disrupted or fade out more quickly in organizations with a supportive and inclusive company culture (Shore et al., 2011; Ashkanasy and Härtel, 2014). In addition, our dataset does not allow us to test for positive contagion effects, such as the contagion of positive emotions, which might act as a potential countervailing force to the negative contagion effects observed. Such positive contagion effects might be powerful enough to stop the contagious spread of negative emotions, cognitions, and behaviors across individuals in the workplace (Barsade, 2002; Sy, Côté, and Saavedra, 2005). We thus strongly support Barsade and colleagues' (2018) call for future research to examine the "tipping points" of social contagion. Specifically, it will be important to find out what happens if positive and negative emotions, cognitions, or behaviors are at play at the same time and which type of contagion will be stronger and why. Moreover, we cannot preclude that the increasing incidence of mental disorders in hiring organizations could beat least partly-due to social processes that go beyond social contagion. An alternative explanation that could be ruled out by future research is that newcomers might encourage employees in the hiring organization to "reveal" their previously existing mental disorders and to seek help (Cepeda-Benito and Short, 1998).

Third, and related to the previous point, our goal was to show that the contagion of mental disorders can take place in a business context and that being exposed to organizational newcomers with a mental disorder history enhances the likelihood that coworkers will develop mental disorders. However, given that the etiology of mental disorders is a highly complex process (Bearden, Jasinska, and Freimer, 2009; Smoller, 2016), it is likely that there are additional causes and triggers for the development of mental disorders, which may be unrelated to the working context. Unfortunately, our data do not enable a more in-depth look into the work-relatedness of psychological problems experienced. But our finding that mental disorders tend to accumulate within certain 
organizations and that individuals leaving these unhealthy organizations are particularly infective supports the assumption that unhealthy working contexts play an important role in the mental health of individuals.

Finally, while we consider that revealing epidemiological patterns is crucial for a comprehensive understanding of mental disorders in and across organizations, our approach should also be considered a first step toward addressing another question: How can organizations protect themselves-and of course their employees-from such an epidemic? Future research could specify the contextual factors promoting or preventing employees' infection through the social contagion effects of mental disorders. Infectious diseases differ in the frequency and intensity of contact required for an infection to happen (Dodds and Watts, 2005). Likewise, in an organizational setting, it would be worthwhile to consider the frequency and intensity of exposure to an "infective" newcomer required for contagion (cf. Hakanen, Perhoniemi, and Bakker, 2014). The spread of mental disorders might further depend on both hard factors, such as team size and organizational structures, and soft factors, such as task interdependence, cohesion, and communication patterns among members of the same team and across departments. We hope we encourage future research examining individual-level, team-level, and organizational-level protective mechanisms, and we call for future studies to develop effective interventions to handle these epidemic effects.

\section{Acknowledgments}

We would like to thank Professor John Wagner and the four anonymous reviewers for their highly insightful feedback and excellent guidance during the review process. We are also very grateful for the comments on earlier versions of this manuscript received from audience members and seminar participants at Technical University of Denmark (DTU), Maastricht University, University of Konstanz, Seeburg Castle University, EPFL, and the Academy of Management Annual Meeting.

\section{ORCID iDs}

Julia M. Kensbock (iD https://orcid.org/0000-0001-8642-1938

Lars Alkærsig (iD https://orcid.org/0000-0003-3137-4526

Carina Lomberg (iD https://orcid.org/0000-0002-1965-5619

\section{REFERENCES}

Agrawal, A., I. Cockburn, and J. McHale 2006 "Gone but not forgotten: Knowledge flows, labor mobility, and enduring social relationships." Journal of Economic Geography, 6: 571-591.

Allen, T. D., S. E. McManus, and J. E. Russell 1999 "Newcomer socialization and stress: Formal peer relationships as a source of support." Journal of Vocational Behavior, 54: 453-470.

Alonso, J., M. Codony, V. Kovess, M. C. Angermeyer, S. J. Katz, J. M. Haro, and J. Almansa 2007 "Population level of unmet need for mental healthcare in Europe." The British Journal of Psychiatry, 190: 299-306.

American Psychiatric Association (APA) 2015 "Introduction to understanding mental disorders: Your guide to DSM-5." 
https://www.psychiatry.org/File\%20Library/Patients-Families/APA_UnderstandingMental-Disorders_Introduction.pdf.

Andrade, L. H., J. Alonso, Z. Mneimneh, J. E. Wells, A. Al-Hamzawi, G. Borges, E. Bromet et al.

2014 "Barriers to mental health treatment: Results from the WHO World Mental Health (WMH) Surveys." Psychological Medicine, 44: 1303-1317.

Angermeyer, M. C., A. Millier, C. Rémuzat, T. Refaï, G. Schomerus, and M. Toumi 2015 "Continuum beliefs and attitudes towards people with mental illness: Results from a national survey in France." International Journal of Social Psychiatry, 61: 297-303.

Arrow, K.

1962 "Economic welfare and the allocation of resources for invention." In R. Nelson (ed.), The Rate and Direction of Inventive Activity: Economic and Social Factors: 609-626. Princeton, NJ: Princeton University Press.

Ashkanasy, N. M., and C. S. Daus 2002 "Emotion in the workplace: The new challenge for managers." Academy of Management Perspectives, 16: 76-86.

Ashkanasy, N. M., and A. D. Dorris 2017 "Emotions in the workplace." Annual Review of Organizational Psychology and Organizational Behavior, 4: 67-90.

Ashkanasy, N. M., and C. E. Härtel 2014 "Positive and negative affective climate and culture: The good, the bad, and the ugly." The Oxford Handbook of Organizational Climate and Culture: 136-152. New York: Oxford University Press.

Ashkanasy, N. M., and R. H. Humphrey 2011 "Current emotion research in organizational behavior." Emotion Review, 3: 214-224.

Ashkanasy, N. M., and G. J. Nicholson 2003 "Climate of fear in organisational settings: Construct definition, measurement and a test of theory." Australian Journal of Psychology, 55: 24-29.

Ayuso-Mateos, J. L., R. Nuevo, E. Verdes, N. Naidoo, and S. Chatterji 2010 "From depressive symptoms to depressive disorders: The relevance of thresholds." The British Journal of Psychiatry, 196: 365-371.

Bakker, A. B., H. V. Van Emmerik, and M. C. Euwema 2006 "Crossover of burnout and engagement in work teams." Work and Occupations, 33: 464-489.

Barney, J. B., and P. M. Wright 1998 "On becoming a strategic partner: The role of human resources in gaining competitive advantage." Human Resource Management, 37: 31-46.

Barrett, P. M., R. M. Rapee, M. M. Dadds, and S. M. Ryan 1996 "Family enhancement of cognitive style in anxious and aggressive children." Journal of Abnormal Child Psychology, 24: 187-203.

Barsade, S. G. 2002 "The ripple effect: Emotional contagion and its influence on group behavior." Administrative Science Quarterly, 47: 644-675.

Barsade, S. G., C. G. Coutifaris, and J. Pillemer 2018 "Emotional contagion in organizational life." Research in Organizational Behavior, 38: 137-151.

Barsade, S. G., and D. E. Gibson 2012 "Group affect: Its influence on individual and group outcomes." Current Directions in Psychological Science, 21: 119-123. 
Bastiampillai, T., S. Allison, and S. Chan

2013 "Is depression contagious? The importance of social networks and the implications of contagion theory." Australian \& New Zealand Journal of Psychiatry, 47: 299-303.

Bauch, C. T., and A. P. Galvani 2013 "Social factors in epidemiology." Science, 342: 47-49.

Bauer, T. N., T. Bodner, B. Erdogan, D. M. Truxillo, and J. S. Tucker 2007 "Newcomer adjustment during organizational socialization: A meta-analytic review of antecedents, outcomes, and methods." Journal of Applied Psychology, 92: 707-721.

Baumeister, R. F., E. Bratslavsky, C. Finkenauer, and K. D. Vohs 2001 "Bad is stronger than good." Review of General Psychology, 5: 323-370.

Bearden, C. E., A. J. Jasinska, and N. B. Freimer 2009 "Methodological issues in molecular genetic studies of mental disorders." Annual Review of Clinical Psychology, 5: 49-69.

Beck, A. T. 1976 Cognitive Therapy and the Emotional Disorders. New York: International Universities Press.

Behrens, D. A., J. P. Caulkins, G. Tragler, and G. Feichtinger 2000 "Optimal control of drug epidemics: Prevent and treat—but not at the same time?"Management Science, 46: 333-347.

Benedict, B. 2007 "Modeling alcohol as a contagious disease: How infected drinking buddies spread problem drinking." SIAM News, 40: 513-536.

Bettencourt, L. M. A., A. Cintrón-Arias, D. I. Kaiser, and C. Castillo-Chávez 2016 "The power of a good idea: Quantitative modeling of the spread of ideas from epidemiological models." Physica A: Statistical Mechanics and Its Applications, 364: 513-536.

Beyer, J. M., and D. R. Hannah 2002 "Building on the past: Enacting established personal identities in a new work setting." Organization Science, 13: 636-652.

Bhui, K. S., S. Dinos, S. A. Stansfeld, and P. D. White 2012 "A synthesis of the evidence for managing stress at work: A review of the reviews reporting on anxiety, depression, and absenteeism." Journal of Environmental and Public Health. DOI: 10.1155/2012/515874.

Bianchi, R., I. S. Schonfeld, and E. Laurent 2017 "Burnout or depression: Both individual and social issue." The Lancet, 390: 230.

Bianchi, R., J. Verkuilen, R. Brisson, I. S. Schonfeld, and E. Laurent 2016 "Burnout and depression: Label-related stigma, help-seeking, and syndrome overlap." Psychiatry Research, 245: 91-98.

Bidwell, M. 2011 "Paying more to get less: The effects of external hiring versus internal mobility." Administrative Science Quarterly, 56: 369-407.

Bonita, R., R. Beaglehole, and T. Kjellström 2006 Basic Epidemiology. Geneva, Switzerland: World Health Organization.

Boyko, M., R. Kutz, J. Grinshpun, V. Zvenigorodsky, S. E. Gruenbaum, B. F. Gruenbaum, E. Brotfain, Y. Shapira, and A. Zlotnik 2015 "Establishment of an animal model of depression contagion." Behavioural Brain Research, 281: 358-363.

Bravo, M., J. Maria Peiró, I. Rodriguez, and T. Whitely 2003 "Social antecedents of the role stress and career-enhancing strategies of newcomers to organizations: A longitudinal study." Work \& Stress, 17: 195-217. 
Brown, I., and D. K. Inouye

1978 "Learned helplessness through modeling: The role of perceived similarity in competence." Journal of Personality and Social Psychology, 36: 900-908.

Bruce, S. E., K. A. Yonkers, M. W. Otto, J. L. Eisen, R. B. Weisberg, M. Pagano, M. T. Shea, and M. B. Keller

2005 "Influence of psychiatric comorbidity on recovery and recurrence in generalized anxiety disorder, social phobia, and panic disorder: A 12-year prospective study." American Journal of Psychiatry, 162: 1179-1187.

Burke, R. J., and C. L. Cooper 2008 The Long Work Hours Culture: Causes, Consequences, and Choices. Bingley, UK: Emerald Insight.

Caballero, B. 2007 "The global epidemic of obesity: An overview." Epidemiologic Reviews, 29: $1-5$.

Cacioppo, J. T., J. H. Fowler, and N. A. Christakis 2009 "Alone in the crowd: The structure and spread of loneliness in a large social network." Journal of Personality and Social Psychology, 97: 977-991.

Cappelli, P., and J. R. Keller 2014 "Talent management: Conceptual approaches and practical challenges." Annual Review of Organizational Psychology and Organizational Behavior, 1: 305-331.

Carr, J. C., A. W. Pearson, M. J. Vest, and S. L. Boyar 2006 "Prior occupational experience, anticipatory socialization, and employee retention." Journal of Management, 32: 343-359.

Cepeda-Benito, A., and P. Short 1998 "Self-concealment, avoidance of psychological services, and perceived likelihood of seeking professional help." Journal of Counseling Psychology, 45: 58-64.

Chatterjee, A., and D. C. Hambrick 2007 "It's all about me: Narcissistic chief executive officers and their effects on company strategy and performance." Administrative Science Quarterly, 52: 351-386.

Cheng, B. H., and J. M. McCarthy 2018 "Understanding the dark and bright sides of anxiety: A theory of workplace anxiety." Journal of Applied Psychology, 103: 537-560.

Chisholm, D., K. Sweeny, P. Sheehan, B. Rasmussen, F. Smit, P. Cuijpers, and

\section{S. Saxena}

2016 "Scaling-up treatment of depression and anxiety: A global return on investment analysis." The Lancet Psychiatry, 3: 415-424.

Christophe, V., and B. Rimé 1997 "Exposure to the social sharing of emotion: Emotional impact, listener responses and secondary social sharing." European Journal of Social Psychology, 27: 37-54.

Clark, L. A., and D. Watson 1991 "Tripartite model of anxiety and depression: Psychometric evidence and taxonomic implications." Journal of Abnormal Psychology, 100: 316-336.

Cohn, J. F., T. S. Kruez, I. Matthews, Y. Yang, M. H. Nguyen, M. T. Padilla, F. Zhou, and F. De La Torre

2009 "Detecting depression from facial actions and vocal prosody." IEEE 3rd International Conference on Affective Computing and Intelligent Interaction and Workshops, Amsterdam, Netherlands: 1-7. DOI: 10.1109/ACII.2009.5349358.

Colligan, M. J., and L. R. Murphy

1982 "A review of mass psychogenic illness in work settings." In M. J. Colligan, J. W. Pennebaker, and L. R. Murphy (eds.), Mass Psychogenic Illness: A Social Psychological Analysis: 35-52. Hillsdale, NJ: Erlbaum. 
Collins, C. J., and K. D. Clark

2003 "Strategic human resource practices, top management team social networks, and firm performance: The role of human resource practices in creating organizational competitive advantage." Academy of Management Journal, 46: 740-751.

Cooper, C. L., and S. Cartwright

1994 "Healthy mind; healthy organization-A proactive approach to occupational stress." Human Relations, 47: 455-471.

Corredoira, R. A., and L. Rosenkopf

2010 "Should auld acquaintance be forgot? The reverse transfer of knowledge through mobility ties." Strategic Management Journal, 31: 159-181.

Crandall, C. S.

1988 "Social contagion of binge eating." Journal of Personality and Social Psychology, 55: 588-598.

Creswell, C., T. G. O'Connor, and C. R. Brewin

2006 "A longitudinal investigation of maternal and child 'anxious cognitions.'

"Cognitive Therapy and Research, 30: 135-147.

Critchley, H. D., and Y. Nagai

2012 "How emotions are shaped by bodily states." Emotion Review, 4: 163-168.

Dahl, M. S., C. L. Dezső, and D. G. Ross

2012 "Fatherhood and managerial style: How a male CEO's children affect the wages of his employees." Administrative Science Quarterly, 57: 669-693.

Dahl, M. S., and L. Pierce

2020a "Pay-for-performance and employee mental health: Large sample evidence using employee prescription drug usage." Academy of Management Discoveries, 6: 12-38.

Dahl, M. S., and L. Pierce

$2020 b$ "When is an effect size too small? Response to commentary on 'Pay-forperformance and employee mental health."' Academy of Management Discoveries, 6: 140-141.

Dasborough, M. T., N. M. Ashkanasy, E. Y. Tee, and H. M. Herman

2009 "What goes around comes around: How meso-level negative emotional contagion can ultimately determine organizational attitudes toward leaders." The Leadership Quarterly, 20: 571-585.

De Croon, E. M., J. K. Sluiter, R. W. Blonk, J. P. Broersen, and M. H. Frings-Dresen 2004 "Stressful work, psychological job strain, and turnover: A 2-year prospective cohort study of truck drivers." Journal of Applied Psychology, 89: 442-454.

De Girolamo, G., J. Dagani, R. Purcell, A. Cocchi, and P. D. McGorry 2012 "Age of onset of mental disorders and use of mental health services: Needs, opportunities and obstacles." Epidemiology and Psychiatric Sciences, 21: 47-57.

Degoey, P.

2000 "Contagious justice: Exploring the social construction of justice in organizations." Research in Organizational Behavior, 22: 51-102.

De Lange, A. H., H. De Witte, and G. Notelaers

2008 "Should I stay or should I go? Examining longitudinal relations among job resources and work engagement for stayers versus movers." Work \& Stress, 22: 201-223.

De Lange, A. H., T. W. Taris, M. A. Kompier, I. L. Houtman, and P. M. Bongers 2005 "Different mechanisms to explain the reversed effects of mental health on work characteristics." Scandinavian Journal of Work, Environment \& Health, 31: 3-14.

Devine, D. J., L. D. Clayton, J. L. Philips, B. B. Dunford, and S. B. Melner 1999 "Teams in organizations: Prevalence, characteristics, and effectiveness." Small Group Research, 30: 678-711. 
Diener, C. I., and C. S. Dweck

1978 "An analysis of learned helplessness: Continuous changes in performance, strategy, and achievement cognitions following failure." Journal of Personality and Social Psychology, 36: 451-462.

Dodds, P. S., and D. J. Watts

2005 "A generalized model of social and biological contagion." Journal of Theoretical Biology, 232: 587-604.

Dokko, G., S. L. Wilk, and N. P. Rothbard

2009 "Unpacking prior experience: How career history affects job performance." Organization Science, 20: 51-68.

Dunford, B. B., A. J. Shipp, R. W. Boss, I. Angermeier, and A. D. Boss 2012 "Is burnout static or dynamic? A career transition perspective of employee burnout trajectories." Journal of Applied Psychology, 97: 637-650.

Ein-Dor, T., M. Mikulincer, G. Doron, and P. R. Shaver 2010 "The attachment paradox: How can so many of us (the insecure ones) have no adaptive advantages?" Perspectives on Psychological Science, 5: 123-141.

Ein-Dor, T., and A. Perry 2014 "Full house of fears: Evidence that people high in attachment anxiety are more accurate in detecting deceit." Journal of Personality, 82: 83-92.

Ein-Dor, T., and O. Tal 2012 "Scared saviors: Evidence that people high in attachment anxiety are more effective in alerting others to threat." European Journal of Social Psychology, 42: 667-671.

Ellis, A. M., T. N. Bauer, L. R. Mansfield, B. Erdogan, D. M. Truxillo, and L. S. Simon 2015 "Navigating uncharted waters: Newcomer socialization through the lens of stress theory." Journal of Management, 41: 203-235.

Equeter, E., D. Jepsen, and C. Hellemans 2018 "Are employees more mobilized after job mobility?" Journal of Career Assessment, 26: 476-487.

Evans, S., S. Ferrando, M. Findler, C. Stowell, C. Smart, and D. Haglin 2008 "Mindfulness-based cognitive therapy for generalized anxiety disorder." Journal of Anxiety Disorders, 22: 716-721.

Eysenck, M. W., N. Derakshan, R. Santos, and M. G. Calvo 2007 "Anxiety and cognitive performance: Attentional control theory." Emotion, 7: 336-353.

Fahrenkopf, E., J. Guo, and I. Argote 2020 "Personnel mobility and organizational performance: The effects of specialist vs. generalist experience and organizational work structure." Organization Science, 31: 1601-1620.

Fang, R., M. K. Duffy, and J. D. Shaw 2011 "The organizational socialization process: Review and development of a social capital model." Journal of Management, 37: 127-152.

Fava, G. A. 1999 "Subclinical symptoms in mood disorders: Pathophysiological and therapeutic implications." Psychological Medicine, 29: 47-61.

Feldman, D. B., and C. S. Crandall 2007 "Dimensions of mental illness stigma: What about mental illness causes social rejection?" Journal of Social and Clinical Psychology, 26: 137-154.

Felps, W., T. R. Mitchell, and E. Byington 2006 "How, when, and why bad apples spoil the barrel: Negative group members and dysfunctional groups." Research in Organizational Behavior, 27: 175-222.

Fila, M. J., J. Purl, and R. W. Griffeth 2017 "Job demands, control and support: Meta-analyzing moderator effects of gender, nationality, and occupation." Human Resource Management Review, 27: 39-60. 
Fiske, S. T.

1980 "Attention and weight in person perception: The impact of negative and extreme behavior." Journal of Personality and Social Psychology, 38: 889-906.

Follmer, K. B., and K. S. Jones

2017 "Mental illness in the workplace: An interdisciplinary review and organizational research agenda." Journal of Management, 44: 325-351.

Fowler, J. H., and N. A. Christakis

2008 "Dynamic spread of happiness in a large social network: Longitudinal analysis over 20 years in the Framingham Heart Study." British Medical Journal. DOI: 10.1136/bmj.a2338.

Frérot, M., A. Lefebvre, S. Aho, P. Callier, K. Astruc, and L. S. A. Glélé 2018 "What is epidemiology? Changing definitions of epidemiology 1978-2017." PloS One, 13(12). DOI: org/10.1371/journal.pone.0208442.

Fryers, T., D. Melzer, and R. Jenkins 2003 "Social inequalities and the common mental disorders." Social Psychiatry and Psychiatric Epidemiology, 38: 229-237.

Gajewski, P. D., S. Boden, G. Freude, G. G. Potter, M. Claus, P. Bröde, C. Watzl, S. Getzmann, and M. Falkenstein 2017 "Executive control, ERP and pro-inflammatory activity in emotionally exhausted middle-aged employees. Comparison between subclinical burnout and mild to moderate depression." Psychoneuroendocrinology, 86: 176-186.

Gamero, N., V. González-Romá, and J. M. Peiró 2008 "The influence of intra-team conflict on work teams' affective climate: A longitudinal study." Journal of Occupational and Organizational Psychology, 81: 47-69.

Garber, J., and C. Flynn 2001 "Predictors of depressive cognitions in young adolescents." Cognitive Therapy and Research, 25: 353-376.

George, G., J. Howard-Grenville, A. Joshi, and L. Tihanyi

2016 "Understanding and tackling societal grand challenges through management research." Academy of Management Journal, 59: 1880-1895.

Glass, K., N. Becker, and M. Clements

2007 "Predicting case numbers during infectious disease outbreaks when some cases are undiagnosed." Statistics in Medicine, 26: 171-183.

Goethals, G. R., and A. L. Perlstein 1978 "Level of instigation and model similarity as determinants of aggressive behavior." Aggressive Behavior, 4: 115-124.

Gomez, R.

2013 "Depression anxiety stress scales: Factor structure and differential item functioning across women and men." Personality and Individual Differences, 54: 687-691.

González, B., E. Huerta-Sánchez, A. Ortiz-Nieves, T. Vázquez-Alvarez, and C. Kribs-Zaleta

2003 "Am I too fat? Bulimia as an epidemic." Journal of Mathematical Psychology, 47: 515-526.

Graen, G. B., and M. Uhl-Bien 1995 "Relationship-based approach to leadership: Development of leader-member exchange (LMX) theory of leadership over 25 years: Applying a multi-level multidomain perspective." The Leadership Quarterly, 6: 219-247.

Greene, W. H. 2011 Econometric Analysis, 7th ed. New York: Pearson Education.

Groysberg, B., L. E. Lee, and A. Nanda 2008 "Can they take it with them? The portability of star knowledge workers' performance." Management Science, 54: 1213-1230. 
Guest, D. E.

2017 "Human resource management and employee well-being: Towards a new analytic framework." Human Resource Management Journal, 27: 22-38.

Gump, B. B., and J. A. Kulik

1997 "Stress, affiliation, and emotional contagion." Journal of Personality and Social Psychology, 72: 305-319.

Gurtman, M. B., K. M. Martin, and N. M. Hintzman

1990 "Interpersonal reactions to displays of depression and anxiety." Journal of Social and Clinical Psychology, 9: 256-267.

Gyllenberg, D., M. Marttila, R. Sund, E. Jokiranta-Olkoniemi, A. Sourander, M. Gissler, and T. Ristikari

2018 "Temporal changes in the incidence of treated psychiatric and

neurodevelopmental disorders during adolescence: An analysis of two national

Finnish birth cohorts." The Lancet Psychiatry, 5: 227-236.

Haeffel, G. J., and J. L. Hames

2014 "Cognitive vulnerability to depression can be contagious." Clinical Psychological Science, 2: 75-85.

Hakanen, J. J., R. Perhoniemi, and A. B. Bakker

2014 "Crossover of exhaustion between dentists and dental nurses." Stress and Health, 30: 110-121.

Hakanen, J. J., W. B. Schaufeli, and K. Ahola

2008 "The Job Demands-Resources model: A three-year cross-lagged study of burnout, depression, commitment, and work engagement." Work \& Stress, 22: 224-241.

Hancock, J. I., D. G. Allen, F. A. Bosco, K. R. McDaniel, and C. A. Pierce 2013 "Meta-analytic review of employee turnover as a predictor of firm performance." Journal of Management, 39: 573-603.

Harkness, A. M., B. C. Long, N. Bermbach, K. Patterson, S. Jordan, and H. Kahn 2005 "Talking about work stress: Discourse analysis and implications for stress interventions." Work \& Stress, 19: 121-136.

Harkness, K. L., J. E. Theriault, J. G. Stewart, and R. M. Bagby 2014 "Acute and chronic stress exposure predicts 1-year recurrence in adult outpatients with residual depression symptoms following response to treatment." Depression and Anxiety, 31: 1-8.

Harvey, S. B., M. Modini, S. Joyce, J. S. Milligan-Saville, L. Tan, A. Mykletun, R. A. Bryant, H. Christensen, and P. B. Mitchell

2017 "Can work make you mentally ill? A systematic meta-review of work-related risk factors for common mental health problems." Occupational and Environmental Medicine, 74: 301-310.

Hatfield, E., J. T. Cacioppo, and R. L. Rapson 1992 "Primitive emotional contagion." Review of Psychology: Emotion and Social Behavior, 14: 25-59.

Hatfield, E., J. T. Cacioppo, and R. L. Rapson 1994 Studies in Emotion and Social Interaction. New York: Cambridge University Press.

Hendriks, S. M., J. Spijker, C. M. Licht, F. Hardeveld, R. S. de Graaf, N. M. Batelaan, B. W. Penninx, and A. T. Beekman

2015 "Long-term work disability and absenteeism in anxiety and depressive disorders." Journal of Affective Disorders, 178: 121-130.

Higgins, M. C. 2006 "Career imprints: Creating leaders across an industry." San Francisco: JosseyBass.

Hill, A. L., D. G. Rand, M. A. Nowak, and N. A. Christakis 2010 "Emotions as infectious diseases in a large social network: The SISa model." Proceedings of the Royal Society B: Biological Sciences, 277: 3827-3835. 
Ho, H., and B. Kuvaas

2020 "Human resource management systems, employee well-being, and firm performance from the mutual gains and critical perspectives: The well-being paradox." Human Resource Management, 59: 235-253.

Hobfoll, S. E., J. Halbesleben, J. P. Neveu, and M. Westman

2018 "Conservation of resources in the organizational context: The reality of resources and their consequences." Annual Review of Organizational Psychology and Organizational Behavior, 5: 103-128.

Ibarra, H., and S. B. Andrews

1993 "Power, social influence, and sense making: Effects of network centrality and proximity on employee perceptions." Administrative Science Quarterly, 38: 277-303.

Ilies, R., D. T. Wagner, and F. P. Morgeson

2007 "Explaining affective linkages in teams: Individual differences in susceptibility to contagion and individualism-collectivism." Journal of Applied Psychology, 92: 1140-1148.

Joiner, T. E., J. M. Buchman-Schmitt, and C. Chu 2017 "Do undiagnosed suicide decedents have symptoms of a mental disorder?" Journal of Clinical Psychology, 73: 1744-1752.

Joiner, T. E., and J. Katz

1999 "Contagion of depressive symptoms and mood: Meta-analytic review and explanations from cognitive, behavioral, and interpersonal viewpoints." Clinical Psychology: Science and Practice, 6: 149-164.

Joyce, S., M. Modini, H. Christensen, A. Mykletun, R. Bryant, P. B. Mitchell, and S. B. Harvey

2016 "Workplace interventions for common mental disorders: A systematic metareview." Psychological Medicine, 46: 683-697.

Judge, T. A., and R. J. Larsen

2001 "Dispositional affect and job satisfaction: A review and theoretical extension." Organizational Behavior and Human Decision Processes, 86: 67-98.

Judge, T. A., J. A. LePine, and B. L. Rich 2006 "Loving yourself abundantly: Relationship of the narcissistic personality to selfand other perceptions of workplace deviance, leadership, and task and contextual performance." Journal of Applied Psychology, 91: 762-776.

Kalish, Y., G. Luria, S. Toker, and M. Westman 2015 "Till stress do us part: On the interplay between perceived stress and communication network dynamics." Journal of Applied Psychology, 100: 1737-1751.

Kantor, J., and D. Streitfeld

2015 "Inside Amazon: Wrestling big ideas in a bruising workplace." The New York Times, Aug. 15. https://www.nytimes.com/2015/08/16/technology/inside-amazonwrestling-big-ideas-in-a-bruising-workplace.html.

Karasek, R. A. 1979 "Job demands, job decision latitude, and mental strain: Implications for job redesign." Administrative Science Quarterly, 24: 285-308.

Kassam-Adams, N., J. F. Garcia-Espana, V. A. Miller, and F. Winston 2006 "Parent-child agreement regarding children's acute stress: The role of parent acute stress reactions." Journal of the American Academy of Child \& Adolescent Psychiatry, 45: 1485-1493.

Kelly, J. R., and S. G. Barsade 2001 "Mood and emotions in small groups and work teams." Organizational Behavior and Human Decision Processes, 86: 99-130.

Kelly, J. R., N. E. lannone, and M. K. McCarty 2016 "Emotional contagion of anger is automatic: An evolutionary explanation." British Journal of Social Psychology, 55: 182-191. 
Keltner, D., and J. Haidt

1999 "Social functions of emotions at four levels of analysis." Cognition \& Emotion, 13: 505-521.

Kermack, W. O., and A. G. McKendrick

1927 "A contribution to the mathematical theory of epidemics." Proceedings of the Royal Society of London A: Mathematical, Physical and Engineering Sciences, 115: 700-721.

Kessler, R. C., G. P. Amminger, S. Aguilar-Gaxiola, J. Alonso, S. Lee, and T. B. Ustun

2007 "Age of onset of mental disorders: A review of recent literature." Current Opinion in Psychiatry, 20: 359-364.

Kessler, R. C., O. Demler, R. G. Frank, M. Olfson, H. A. Pincus, E. E. Walters, P. Wang, K. B. Wells, and A. M. Zaslavsky 2005 "Prevalence and treatment of mental disorders, 1990 to 2003." New England Journal of Medicine, 352: 2515-2523.

Kidwell, R. E., K. A. Eddleston, and F. W. Kellermanns

2018 "Learning bad habits across generations: How negative imprints affect human resource management in the family firm." Human Resource Management Review, 28: 5-17.

Kim, Y. J., and S. M. Toh

2019 "Stuck in the past? The influence of a leader's past cultural experience on group culture and positive and negative group deviance." Academy of Management Journal, 62: 944-969.

Köppe, C., J. Kammerhoff, and A. Schütz

2018 "Leader-follower crossover: Exhaustion predicts somatic complaints via StaffCare behavior." Journal of Managerial Psychology, 33: 297-310.

Kraemer, M. U., C. H. Yang, B. Gutierrez, C. H. Wu, B. Klein, D. M. Pigott, and J.S. Brownstein

2020 "The effect of human mobility and control measures on the COVID-19 epidemic in China." Science, 368: 493-497.

Krämer, A., M. Akmatov, and M. Kretzschmar 2010 "Principles of infectious disease epidemiology." In A. Krämer, M. Kretzschmar, and K. Krickeberg (eds.), Modern Infectious Disease Epidemiology: 85-100. New York: Springer.

Kramer, A. D., J. E. Guillory, and J. T. Hancock 2014 "Experimental evidence of massive-scale emotional contagion through social networks." Proceedings of the National Academy of Sciences, 111: 8788-8790.

Kramer, U., J. N. Despland, L. Michel, M. Drapeau, and Y. de Roten 2010 "Change in defense mechanisms and coping over the course of short-term dynamic psychotherapy for adjustment disorder." Journal of Clinical Psychology, 66: 1232-1241.

Kruglanski, A. W., and O. Mayseless 1990 "Classic and current social comparison research: Expanding the perspective." Psychological Bulletin, 108: 195-208.

Latané, $\mathrm{B}$.

2000 "Pressures to uniformity and the evolution of cultural norms: Modeling dynamic social impact." In D. R. Ilgen and C. L. Hulin (eds.), Computational Modeling of Behavior in Organizations: The Third Scientific Discipline: 189-216. Westport, CT: Quorum Books.

Le Bon, G.

1903 The Crowd: A Study of the Popular Mind, 4th imprinting. London: T. Fisher Unwin. (Originally published as Psychologie des foules, 1895.) 
Levy, D. A., and P. R. Nail

1993 "Contagion: A theoretical and empirical review and reconceptualization."

Genetic, Social, and General Psychology Monographs, 119: 233-284.

Liljegren, M., and K. Ekberg

2009 "Job mobility as predictor of health and burnout." Journal of Occupational and Organizational Psychology, 82: 317-329.

Liu, S., M. Wang, P. Bamberger, J. Shi, and S. B. Bacharach

2015 "The dark side of socialization: A longitudinal investigation of newcomer alcohol use." Academy of Management Journal, 58: 334-355.

Lovibond, P. F., and S. H. Lovibond

1995 "The structure of negative emotional states: Comparison of the Depression Anxiety Stress Scales (DASS) with the Beck Depression and Anxiety Inventories." Behaviour Research and Therapy, 33: 335-343.

MacMahon, B., and T. F. Pugh

1970 Epidemiology: Principles and Methods. Boston: Little, Brown and Company.

Mark, G., and A. P. Smith

2012a "Occupational stress, job characteristics, coping, and the mental health of nurses." British Journal of Health Psychology, 17: 505-521.

Mark, G., and A. P. Smith

2012b "Effects of occupational stress, job characteristics, coping, and attributional style on the mental health and job satisfaction of university employees." Anxiety, Stress \& Coping, 25: 63-78.

Mathers, C. D., and D. Loncar 2006 "Projections of global mortality and burden of disease from 2002 to 2030." Plos Med, 3(11): e442. DOI: 10.1371/journal.pmed.0030442.

Mawdsley, J. K., and D. Somaya 2016 "Employee mobility and organizational outcomes: An integrative conceptual framework and research agenda." Journal of Management, 42: 85-113.

McCulloch, M. C., and D. B. Turban 2007 "Using person-organization fit to select employees for high-turnover jobs." International Journal of Selection and Assessment, 15: 63-71.

McEvily, B., J. Jaffee, and M. Tortoriello 2011 "Not all bridging ties are equal: Network imprinting and firm growth in the Nashville legal industry, 1933-1978." Organization Science, 23: 547-563.

McTernan, W. P., M. F. Dollard, and A. D. LaMontagne 2013 "Depression in the workplace: An economic cost analysis of depression-related productivity loss attributable to job strain and bullying." Work \& Stress, 27: 321-338.

Melchior, M., A. Caspi, B. J. Milne, A. Danese, R. Poulton, and T. E. Moffitt 2007 "Work stress precipitates depression and anxiety in young, working women and men." Psychological Medicine, 37: 1119-1129.

Mikkelsen, M. B., and M. Rosholm 2018 "Systematic review and meta-analysis of interventions aimed at enhancing return to work for sick-listed workers with common mental disorders, stress-related disorders, somatoform disorders and personality disorders." Occupational and Environmental Medicine, 75: 675-686.

Mirnezami, H. F., L. Jacobsson, and A. Edin-Liljegren 2016 "Changes in attitudes towards mental disorders and psychiatric treatment 1976-2014 in a Swedish population." Nordic Journal of Psychiatry, 70: 38-44.

Mittendorfer-Rutz, E., L. Kjeldgård, B. Runeson, A. Perski, M. Melchior, J. Head, and K. Alexanderson

2012 "Sickness absence due to specific mental diagnoses and all-cause and causespecific mortality: A cohort study of 4.9 million inhabitants of Sweden." PloS One, 7(9): e45788. DOI: 10.1371/journal.pone.0045788. 
Mor Barak, M. E., J. A. Nissly, and A. Levin

2001 "Antecedents to retention and turnover among child welfare, social work, and other human service employees: What can we learn from past research? A review and metanalysis." Social Service Review, 75: 625-661.

Moreno, Y., M. Nekovee, and A. F. Pacheco 2004 "Dynamics of rumor spreading in complex networks." Physical Review E, 69: $1-7$.

Mueller, T. I., A. C. Leon, M. B. Keller, D. A. Solomon, J. Endicott, W. Coryell, M. Warshaw, and J. D. Maser

1999 "Recurrence after recovery from major depressive disorder during 15 years of observational follow-up." American Journal of Psychiatry, 156: 1000-1006.

Nahrgang, J. D., F. P. Morgeson, and D. A. Hofmann 2011 "Safety at work: A meta-analytic investigation of the link between job demands, job resources, burnout, engagement, and safety outcomes." Journal of Applied Psychology, 96: 71-94.

Netterstrøm, B., N. Conrad, P. Bech, P. Fink, O. Olsen, R. Rugulies, and S. Stansfeld 2008 "The relation between work-related psychosocial factors and the development of depression." Epidemiologic Reviews, 30: 118-132.

Newman, M. E. 2002 "Spread of epidemic disease on networks." Physical Review E, 66: 1-11.

Nieuwenhuijsen, K., D. Bruinvels, and M. Frings-Dresen 2010 "Psychosocial work environment and stress-related disorders, a systematic review." Occupational Medicine, 60: 277-286.

Owen, J., L. Thomas, and E. Rodolfa 2013 "Stigma for seeking therapy: Self-stigma, social stigma, and therapeutic processes." The Counseling Psychologist, 41: 857-880.

Parke, M. R., and M. G. Seo 2017 "The role of affect climate in organizational effectiveness." Academy of Management Review, 42: 334-360.

Patten, S. B. 1999 "Epidemics of violence." Medical Hypotheses, 53: 217-220.

Patten, S. B., and J. A. Arboleda-Flórez 2004 "Epidemic theory and group violence." Social Psychiatry and Psychiatric Epidemiology, 39: 853-856.

Pearsall, M. J., A. P. Ellis, and J. H. Stein 2009 "Coping with challenge and hindrance stressors in teams: Behavioral, cognitive, and affective outcomes." Organizational Behavior and Human Decision Processes, 109: 18-28.

Peccei, R., and K. Van De Voorde 2019 "Human resource management-well-being-performance research revisited: Past, present, and future." Human Resource Management Journal, 29: 539-563.

Peeters, G., and J. Czapinski 1990 "Positive-negative asymmetry in evaluations: The distinction between affective and informational negativity effects." European Review of Social Psychology, 1: 33-60.

Perrings, C., C. Castillo-Chavez, G. Chowell, P. Daszak, E. P. Fenichel, D. Finnoff, R. D. Horan et al.

2014 "Merging economics and epidemiology to improve the prediction and management of infectious disease." EcoHealth, 11: 464-475.

Porta, M. (ed.) 2014 A Dictionary of Epidemiology. New York: Oxford University Press. 
Raffiee, J., and H. Byun

2020 "Revisiting the portability of performance paradox: Employee mobility and the utilization of human and social capital resources." Academy of Management Journal, 63: 34-63.

Rajan, R. G., and J. Wulf 2006 "The flattening firm: Evidence from panel data on the changing nature of corporate hierarchies." Review of Economics and Statistics, 88: 759-773.

Rao, H., and R. Drazin 2002 "Overcoming resource constraints on product innovation by recruiting talent from rivals: A study of the mutual fund industry, 1986-1994." Academy of Management Journal, 45: 491-507.

Reineholm, C., M. Gustavsson, M. Liljegren, and K. Ekberg 2012 "The importance of work conditions and health for voluntary job mobility: A two-year follow-up." BMC Public Health, 12: 1-7.

Richards, D. 2011 "Prevalence and clinical course of depression: A review." Clinical Psychology Review, 31: 1117-1125.

Rimé, $\mathrm{B}$. 2009 "Emotion elicits the social sharing of emotion: Theory and empirical review." Emotion Review, 1: 60-85.

Rodríguez, I., M. W. Kozusznik, J. M. Peiró, and N. Tordera 2019 "Individual, co-active and collective coping and organizational stress: A longitudinal study." European Management Journal, 37: 86-98.

Rosenkopf, L., and P. Almeida 2003 "Overcoming local search through alliances and mobility." Management Science, 49: 751-766.

Rosenquist, J. N., J. H. Fowler, and N. A. Christakis

2011 "Social network determinants of depression." Molecular Psychiatry, 16: 273-281.

Rosenquist, J. N., J. Murabito, J. H. Fowler, and N. A. Christakis 2010 "The spread of alcohol consumption behavior in a large social network." Annals of Internal Medicine, 152: 426-433.

Rottinghaus, P. J., N. Jenkins, and A. M. Jantzer 2009 "Relation of depression and affectivity to career decision status and selfefficacy in college students." Journal of Career Assessment, 17: 271-285.

Saks, A. M. 1994 "Moderating effects of self-efficacy for the relationship between training method and anxiety and stress reactions of newcomers." Journal of Organizational Behavior, 15: 639-654.

Saks, A. M., and J. A. Gruman 2011 "Getting newcomers engaged: The role of socialization tactics." Journal of Managerial Psychology, 26: 383-402.

Salancik, G. R., and J. Pfeffer 1978 "A social information processing approach to job attitudes and task design." Administrative Science Quarterly, 23: 224-253.

Salanova, M., S. Llorens, E. Cifre, and I. M. Martínez 2012 "We need a hero! Toward a validation of the healthy and resilient organization (HERO) model." Group \& Organization Management, 37: 785-822.

Santini, Z. I., A. Koyanagi, S. Tyrovolas, C. Mason, and J. M. Haro 2015 "The association between social relationships and depression: A systematic review." Journal of Affective Disorders, 175: 53-65.

Sapolsky, R. M.

2006 "Stress, stress-related disease, and emotion regulation." In J. J. Gross (ed.), Handbook of Emotion Regulation: 606-615. New York: Guilford Press. 
Schaefer, J. D., A. Caspi, D. W. Belsky, H. Harrington, R. Houts, L. J. Horwood, L. H. Horwood et al.

2017 "Enduring mental health: Prevalence and prediction." Journal of Abnormal Psychology, 126: 212-224.

Schomerus, G., and M. C. Angermeyer

2008 "Stigma and its impact on help-seeking for mental disorders: What do we know?" Epidemiology and Psychiatric Sciences, 17: 31-37.

Schwartz-Mette, R. A., and A. J. Rose

2012 "Co-rumination mediates contagion of internalizing symptoms within youths' friendships." Developmental Psychology, 48: 1355-1365.

Seedat, S., K. M. Scott, M. C. Angermeyer, P. Berglund, E. J. Bromet, T. S. Brugha, and K. Demyttenaere et al.

2009 "Cross-national associations between gender and mental disorders in the World Health Organization World Mental Health Surveys." Archives of General Psychiatry, 66: 785-795.

Seligman, M. E. P.

2002 "Positive psychology, positive prevention, and positive therapy." In C. R.

Snyder and S. J. Lopez (eds.), Handbook of Positive Psychology: 3-9. Oxford: Oxford University Press.

Shore, L. M., A. E. Randel, B. G. Chung, M. A. Dean, K. Holcombe Ehrhart, and G. Singh

2011 "Inclusion and diversity in work groups: A review and model for future research." Journal of Management, 37: 1262-1289.

Shu, J., S. Hassell, J. Weber, K. N. Ochsner, and D. Mobbs

2017 "The role of empathy in experiencing vicarious anxiety." Journal of Experimental Psychology, 146: 1164-1188.

Singh, J., and A. Agrawal

2011 "Recruiting for ideas: How firms exploit the prior inventions of new hires." Management Science, 57: 129-150.

Smith, K. F., D. F. Sax, S. D. Gaines, V. Guernier, and J.-F. Guégan 2007 "Globalization of human infectious disease." Ecology, 88: 1903-1910.

Smoller, J. W.

2016 "The genetics of stress-related disorders: PTSD, depression, and anxiety disorders." Neuropsychopharmacology, 41: 297-319.

Song, J., P. Almeida, and G. Wu 2003 "Learning-by-hiring: When is mobility more likely to facilitate interfirm knowledge transfer?" Management Science, 49 :351-365.

Southwick, S. M., M. Vythilingam, and D. S. Charney 2005 "The psychobiology of depression and resilience to stress: Implications for prevention and treatment." Annual Review of Clinical Psychology, 1: 255-291.

Stansfeld, S., and B. Candy 2006 "Psychosocial work environment and mental health-a meta-analytic review." Scandinavian Journal of Work, Environment \& Health, 32: 443-462.

Stansfeld, S. A., F. R. Rasul, J. Head, and N. Singleton 2011 "Occupation and mental health in a national UK survey." Social Psychiatry and Psychiatric Epidemiology, 46: 101-110.

Stark, K. D., K. L. Schmidt, and T. E. Joiner 1996 "Cognitive triad: Relationship to depressive symptoms, parents' cognitive triad, and perceived parental messages." Journal of Abnormal Child Psychology, 24: 615-631.

Staw, B. M., and J. Ross 1985 "Stability in the midst of change: A dispositional approach to job attitudes." Journal of Applied Psychology, 70: 469-480. 
Steel, Z., C. Marnane, C. Iranpour, T. Chey, J. W. Jackson, V. Patel, and D. Silove 2014 "The global prevalence of common mental disorders: A systematic review and meta-analysis 1980-2013." International Journal of Epidemiology, 43: 476-493.

Straif-Bourgeois, S., R. Ratard, and M. Kretzschmar 2014 "Infectious disease epidemiology." In W. Ahrens and I. Pigeot (eds.), Handbook of Epidemiology: 2041-2120. New York: Springer.

Summers, J. K., S. E. Humphrey, and G. R. Ferris 2012 "Team member change, flux in coordination, and performance: Effects of strategic core roles, information transfer, and cognitive ability." Academy of Management Journal, 55: 314-338.

Suzuki, T., K. Miyaki, Y. Song, A. Tsutsumi, N. Kawakami, A. Shimazu, M. Takahashi, A. Inoue, and S. Kurioka 2015 "Relationship between sickness presenteeism (WHO-HPQ) with depression and sickness absence due to mental disease in a cohort of Japanese workers." Journal of Affective Disorders, 180: 14-20.

Swaen, G. M., I. Kant, L. G. van Amelsvoort, and A. J. Beurskens 2002 "Job mobility, its determinants, and its effects: Longitudinal data from the Maastricht cohort study." Journal of Occupational Health Psychology, 7: 121-129.

Sy, T., and J. N. Choi 2013 "Contagious leaders and followers: Exploring multi-stage mood contagion in a leader activation and member propagation (LAMP) model." Organizational Behavior and Human Decision Processes, 122: 127-140.

Sy, T., S. Côté, and R. Saavedra

2005 "The contagious leader: Impact of the leader's mood on the mood of group members, group affective tone, and group processes." Journal of Applied Psychology, 90: 295-305.

Taylor, S. E.

1991 "Asymmetrical effects of positive and negative events: The mobilizationminimization hypothesis." Psychological Bulletin, 110: 67-85.

Tebeka, S., B. Pignon, A. Amad, Y. Le Strat, C. Brichant-Petitjean, P. Thomas, and G. Vaiva et al.

2018 "A study in the general population about sadness to disentangle the continuum from well-being to depressive disorders." Journal of Affective Disorders, 226: 66-71.

Tee, E. Y.

2015 "The emotional link: Leadership and the role of implicit and explicit emotional contagion processes across multiple organizational levels." The Leadership Quarterly, 26: 654-670.

Ten Have, M., R. de Graaf, J. Ormel, G. Vilagut, V. Kovess, and J. Alonso 2010 "Are attitudes towards mental health help-seeking associated with service use? Results from the European Study of Epidemiology of Mental Disorders." Social Psychiatry and Psychiatric Epidemiology, 45: 153-163.

Teodorescu, K., and I. Erev 2014 "Learned helplessness and learned prevalence: Exploring the causal relations among perceived controllability, reward prevalence, and exploration." Psychological Science, 25: 1861-1869.

Theorell, T., A. Hammarström, G. Aronsson, L. T. Bendz, T. Grape, C. Hogstedt, I. Marteinsdottir, I. Skoog, and C. Hall 2015 "A systematic review including meta-analysis of work environment and depressive symptoms." BMC Public Health, 15. https://doi.org/10.1186/s12889-015-1954-4.

Thieme, H. R.

1977 "A model for the spatial spread of an epidemic." Journal of Mathematical Biology, 4: 337-351. 
Tilcsik, A.

2014 "Imprint-environment fit and performance: How organizational munificence at the time of hire affects subsequent job performance." Administrative Science Quarterly, 59: 639-668.

Totterdell, $\mathrm{P}$.

2000 "Catching moods and hitting runs: Mood linkage and subjective performance in professional sport teams." Journal of Applied Psychology, 85: 848-859.

Totterdell, P., M. S. Hershcovis, K. Niven, T. C. Reich, and C. Stride 2012 "Can employees be emotionally drained by witnessing unpleasant interactions between coworkers? A diary study of induced emotion regulation." Work \& Stress, 26: 112-129.

Tsai, J., E. Bowring, S. Marsella, and M. Tambe 2011 "Empirical evaluation of computational emotional contagion models." Intelligent Virtual Agents, 11: 384-397.

Twenge, J. M., A. B. Cooper, T. E. Joiner, M. E. Duffy, and S. G. Binau 2019 "Age, period, and cohort trends in mood disorder indicators and suicide-related outcomes in a nationally representative dataset, 2005-2017." Journal of Abnormal Psychology, 128: 185-199.

Van Gelderen, B. R., A. B. Bakker, E. Konijn, and C. Binnewies 2014 "Daily deliberative dissonance acting among police officers." Journal of Managerial Psychology, 29: 884-900.

Vos, T., A. D. Flaxman, M. Naghavi, R. Lozano, C. Michaud, M. Ezzati, and K. Shibuya et al. 2012 "Years lived with disability (YLDs) for 1160 sequelae of 289 diseases and injuries 1990-2010: A systematic analysis for the Global Burden of Disease Study 2010." The Lancet, 380: 2163-2196.

Vyas, A., A. G. Pillai, and S. Chattarji

2004 "Recovery after chronic stress fails to reverse amygdaloid neuronal hypertrophy and enhanced anxiety-like behavior." Neuroscience, 128: 667-673.

Wallbott, H. G., and K. R. Scherer 1991 "Stress specificities: Differential effects of coping style, gender, and type of stressor on autonomic arousal, facial expression, and subjective feeling." Journal of Personality and Social Psychology, 61: 147-156.

Wang, P. S., P. Berglund, M. Olfson, H. A. Pincus, K. B. Wells, and R. C. Kessler 2005 "Failure and delay in initial treatment contact after first onset of mental disorders in the National Comorbidity Survey Replication." Archives of General Psychiatry, 62: 603-613.

Wang, Y., M. A. Beydoun, L. Liang, B. Caballero, and S. K. Kumanyika 2008 "Will all Americans become overweight or obese? Estimating the progression and cost of the US obesity epidemic." Obesity, 16: 2323-2330.

Waters, S. F., T. V. West, and W. B. Mendes 2014 "Stress contagion: Physiological covariation between mothers and infants." Psychological Science, 25: 934-942.

Weissman, J., D. Russell, M. Jay, J. M. Beasley, D. Malaspina, and C. Pegus 2017 "Disparities in health care utilization and functional limitations among adults with serious psychological distress, 2006-2014." Psychiatric Services, 68: 653-659.

Wesselhoeft, R., C. B. Pedersen, P. B. Mortensen, O. Mors, and N. Bilenberg 2015 "Gender-age interaction in incidence rates of childhood emotional disorders." Psychological Medicine, 45: 829-839.

Westman, $\mathrm{M}$. 2001 "Stress and strain crossover." Human Relations, 54: 717-751.

Westman, M., and D. Etzion 1999 "The crossover of strain from school principals to teachers and vice versa." Journal of Occupational Health Psychology, 4: 269-278. 
Wheeler, L.

1966 "Toward a theory of behavioral contagion." Psychological Review, 73: 179-192.

Wheeler, L., and A. R. Caggiula

1966 "The contagion of aggression." Journal of Experimental Social Psychology, 2: $1-10$.

Wiklund, J., I. Hatak, H. Patzelt, and D. A. Shepherd

2018 "Mental disorders in the entrepreneurship context: When being different can be an advantage." Academy of Management Perspectives, 32: 182-206.

Wooldridge, J. M.

2004 Econometric Analysis of Cross Section and Panel Data, 2nd ed. Cambridge, MA: MIT Press.

World Health Organization (WHO)

2019 "Mental disorders." Nov. 28. https://www.who.int/news-room/fact-sheets/ detail/mental-disorders.

Wright, T. A., and D. G. Bonett

1992 "The effect of turnover on work satisfaction and mental health: Support for a situational perspective." Journal of Organizational Behavior, 13: 603-615.

Yokoya, S., T. Maeno, N. Sakamoto, R. Goto, and T. Maeno

2018 "A brief survey of public knowledge and stigma towards depression." Journal of Clinical Medicine Research, 10: 202-209.

Zagenczyk, T. J., E. E. Powell, and K. L. Scott 2020 "How exhausting!? Emotion crossover in organizational social networks." Journal of Management Studies. DOI: 10.1111/joms.12557.

Zhou, Y., M. Zou, M. Williams, and V. Tabvuma

2017 "Is the grass greener on the other side? A longitudinal study of the impact of employer change and occupational change on job satisfaction." Journal of Vocational Behavior, 99: 66-78.

\section{Authors' Biographies}

Julia M. Kensbock is an assistant professor at Maastricht University, School of Business and Economics, Department of Organization, Strategy, and Entrepreneurship, Tongersestraat 53, 6211 LM Maastricht, The Netherlands (j.kensbock@maastricht university.nl). Her research is located at the interface between psychology and management and explores the "dark side" of work, especially its negative effects on individuals" well-being.

Lars Alkærsig is an associate professor at the Centre for Technology Entrepreneurship, Technical University of Denmark, Diplomvej 371, 206, DK-2800 Kgs. Lyngby, Denmark (lalk@dtu.dk). His research explores the interrelations between entrepreneurship, physical and mental health, and demographic and cognitive diversity. He obtained his Ph.D. in innovation management from Copenhagen Business School, Denmark.

Carina Lomberg is an associate professor at the Centre for Technology Entrepreneurship, Technical University of Denmark, Diplomvej 371, 205, DK-2800 Kgs. Lyngby, Denmark (calom@dtu.dk). Her research focuses on the psychology of entrepreneurship, including (nascent) entrepreneurial behavior, team dynamics, and mental health. 